\title{
Joint Pricing and Inventory Model for Deteriorating Items with Maximum Lifetime and Controllable Carbon Emissions under Permissible Delay in Payments
}

\author{
Arash Sepehri ${ }^{1}$, Umakanta Mishra ${ }^{2} \mathbb{D}$, Ming-Lang Tseng ${ }^{3}$ and Biswajit Sarkar ${ }^{4, *(\mathbb{D}}$ \\ 1 School of Industrial Engineering, Iran University of Science and Technology, Tehran 16846-13114, Iran; \\ arashsepehri72@gmail.com \\ 2 Department of Mathematics, School of Advanced Sciences, Vellore Institute of Technology, \\ Vellore 632014, India; umakanta.mishra@vit.ac.in or umakanta.math@gmail.com \\ 3 Institute of Innovation and Circular Economy, Asia University, Taichung 41354, Taiwan; \\ tsengminglang@asia.edu.tw or tsengminglang@gmail.com \\ 4 Department of Industrial Engineering, Yonsei University, 50 Yonsei-ro, Sinchon-dong, \\ Seodaemun-gu, Seoul 03722, Korea \\ * Correspondence: bsbiswajitsarkar@gmail.com
}

check for updates

Citation: Sepehri, A.; Mishra, U.; Tseng, M.-L.; Sarkar, B. Joint Pricing and Inventory Model for

Deteriorating Items with Maximum Lifetime and Controllable Carbon Emissions under Permissible Delay in Payments. Mathematics 2021, 9, 470 https://doi.org/10.3390/math9050470

Academic Editor:

Anatoliy Swishchuk

Received: 26 January 2021

Accepted: 18 February 2021

Published: 25 February 2021

Publisher's Note: MDPI stays neutral with regard to jurisdictional claims in published maps and institutional affiliations.

Copyright: (c) 2021 by the authors. Licensee MDPI, Basel, Switzerland. This article is an open access article distributed under the terms and conditions of the Creative Commons Attribution (CC BY) license (https:/ / creativecommons.org/licenses/by/ $4.0 /)$.

\begin{abstract}
Reducing carbon emissions plays a significant role in developing sustainable inventory systems. In a seller-buyer relationship, an allowable delay in payment is considered for the buyer to manage the stock and simulate the demand. Deteriorating items that usually have specific maximum lifetimes have become a challenge for most firms. Contrary to the importance of these issues, very little research has studied the impact of carbon emissions on deteriorating inventory systems. This paper provides a price-dependent demand for perishable items when carbon cap-and-trade regulation fills the mentioned gap. This model provides a carbon reduction investment scheme and illustrates this investment's effect on the inventory system. This paper determines the optimal replenishment cycle and selling price, in which: (a) perishable items have specific maximum lifetimes, (b) a specific period of delay in payment is allowed for the buyer to accumulate revenue, (c) carbon is emitted due to ordering and storage operations and carbon cap and trade is regulated along with allowable carbon reduction investment. After developing the model, optimal values are obtained from necessary and sufficient conditions of optimality. Numerical experiments are proposed to validate the model. By developing an algorithm, the optimal values of replenishment cycle, selling price, and carbon reduction technology investment are obtained, and the impact of carbon emissions and efforts to control emissions are outlined. Finally, some managerial applications are mentioned, and future research directions are exposed.
\end{abstract}

Keywords: controllable carbon emission; inventory control; trade credit; deterioration; pricing

\section{Introduction}

In the last two decades, governmental and non-governmental organizations have concentrated on regulating carbon emissions policies and protecting the environment $[1,2]$. In this regard, they organized conferences to achieve efficient policies, and the Kyoto protocol was one of the essential regulations [3]. Addressing the impact of carbon emissions in inventory systems has become significant. Regulating different carbon emission policies is crucial in restricting emissions. One of the first papers investigating the carbon emission policies in an inventory system is by Hua et al. [4]. They discussed carbon cap-and-trade regulation as an encouraging means to reduce emissions in an inventory system. In this policy, the government allocates a carbon cap to the firms, which is an allowance for emissions, and if the firms emit less than the cap, they can sell the remainder and accumulate revenue. Another solution to the challenge of carbon emissions is investing in carbon reduction technologies and carbon policies to mitigate emissions' impact on an 
inventory system. This idea was first proposed by Toptal et al. [5], who indicated that investing in carbon emission reduction technologies can reduce emissions by a fraction. Additionally, a trade-off between the investment in carbon emission reduction technology and decreased costs associated with emissions must be considered [6].

Deterioration of items caused by spoilage, dryness, and vaporization is another challenge that firms confront [7]. Many works have been carried out to address the challenge of the deterioration in inventory systems. One of the essential papers is by Wu et al. [8], who considered specific expiration dates for deteriorating items. Additionally, considering the trade credit period to stimulate the demand for deteriorating items is another novelty in their work. Later, Tiwari et al. [9] extended this model for two trade credit levels when pricing is another decision, and partial backordering is permissible. In this paper, a price-dependent demand is extended to indicate the decreasing impact of selling price on demand. Adding environmental considerations such as carbon emission regulation to deteriorating inventory models addresses an issue in practice $[10,11]$.

As most companies consider sustainability criteria in the inventory systems, and the deterioration of items is another challenge, more studies are required to elaborate sustainable inventory models for deteriorating items. Despite the significance of the mentioned issues, there is a lack of proposals of models for deteriorating items considering carbon emissions. Considering these gaps, three questions arise: (1) What are the main reasons for emissions in an inventory system? (2) How is the deterioration rate defined, and the trade credit discussed? (3) How to formulate a sustainable inventory system, and what emission policies are appropriate? For these questions, this paper aims to include both deterioration and environmental concerns in an inventory model to help decision makers to adopt optimal replenishment cycles, selling price, and carbon emission reduction technology. This paper's main contribution in relation to the previous papers is to collaborate on deterioration and carbon emissions when the delay in payment is permissible. In addition, considering expiration dates for items and allowable investment in carbon reduction technology are other novelties of this paper.

The rest of the sections are illustrated as follows. Concise literature on deteriorating inventory considering trade credit policy and inventory models considering carbon emissions are discussed in Section 2. In Section 3, notation and assumptions are discussed. Developed models for our elaboration are proposed in Section 4 . Section 5 concentrates on providing appropriate solution procedures for our elaboration. In Section 6, some numerical examples and sensitivity analysis based on a case study are introduced to validate the model. Managerial applications are derived from sensitivity analysis as well. Section 7 concludes the findings and recommends future research directions.

\section{Literature Review}

A concise survey of the literature on deteriorating sustainable inventory models is studied in this section. Finally, relevant research gaps and the approach of this study to fill the gaps are outlined.

Goyal [12] first presented an inventory model considering the delay in payment. This paper was extended by Aggarwal and Jaggi [13] for deteriorating items. Kim et al. [14] proposed the first pricing model considering the delay in payment. Later, hybrid stock and price-dependent (Teng and Chang [15], Tsao and Sheen [16]) demands were developed. Chung and Wee [17] developed a perishable inventory model considering defective items in manufacturing. Sarkar [18] first provided a perishable model considering the maximum lifetime. This paper's many extensions are presented by developing credit and price-dependent demand functions and trade credit policy $[8,9,19]$. Chen and Sarker [20] proposed another model considering multi-items and price-dependent demand for deteriorating items. Wu et al. [21] discussed the difference between cash payment, advance payment, and credit payment for perishable items with a maximum lifetime. A random maximum lifetime using a uniform distribution function is extended by Tai et al. [22]. Mishra et al. [23] proposed a model with hybrid price stock-dependent demand and pro- 
vided conditions of concavity. The solution procedure of this study is utilized in this paper. One of the combinations of deterioration considering maximum lifetime and carbon emission policy is discussed by Shi et al. [24] that compared cash, credit, and advance payment considering carbon tax policy. Considering an expiration date-dependent demand and a trade credit dependent on the amount of order quantity is another approach presented by Yang [25]. Partial trade credit for deteriorating items with an allowable shortage is developed by Tiwari et al. [26]. Saren et al. [27] elaborated a model for perishable items analyzing the price discount when the delay in payment is permissible in the inventory system. Sarkar et al. [28] proposed a model considering the demand dependent on both selling price and trade credit period. They optimized the retailer's replenishment cycle. Elaborating an advanced payment scheme, Khan et al. [29] provided a model for perishable items with an expiration date when the advertisement for items and partial backordering are allowable. They developed a demand function dependent on advertisement and selling price when the holding cost time varies linearly. Das et al. [30] proposed a production model for deteriorating items and considered a manufacturing process's reliability coefficient. They considered two levels of trade credit with prepayment, and items deteriorate at a constant rate. Developing a lot-sizing for growing nonlinear items, Sebatjane and Adetunji [31] proposed a model for perishable items when the demand is dependent on the in-hand stock and freshness (expiration date). Huang et al. [32] proposed a coordinated model for item deterioration with a Weibull distribution function when quantity discount is permissible. Das et al. [33] proposed a model for deteriorating items considering permissible preservation technology investment and trade credit policy.

Considering ordering and holding operations as the main sources of emission, Hua et al. [4] first presented an inventory model under carbon cap and trade. Later, Jaber et al. [34] proposed the first model with carbon reduction investment, and this work was developed by Krass et al. [10], utilizing a price-dependent demand. Toptal et al. [5] took purchasing as another source of emissions for the first time and compared various emission policies. Dye and Yang [35] developed a deteriorating model with carbon emissions for considering trade credit. More operations such as setup [36,37], transportation [36,38-41], manufacturing $[6,10,11,34,42,43]$, and disposing of the obsolete items [37-39] have been considered as main sources of carbon emissions in other works. Lou et al. [6] and Yang et al. [41] defined price- and carbon emission-dependent demand and proposed a model considering emissions due to manufacturing and allowable reduction investment. This paper was followed by adding trade credit (Qin et al. [43]) and considering a price-dependent demand function [44]. Mishra et al. [44] extended Hua et al.'s [4] model with deteriorating items by considering a hybrid price and stock-dependent demand. Lu et al. [36] proposed a Stackelberg gaming approach for deteriorating items when carbon emissions can be controlled by investing in carbon emission reduction technology. Shaw et al. [45] elaborated a coordinated model considering transportation operation of the vendor as the main source of emissions when constant and variable costs are considered for carbon emissions. In addition, they developed the model for decaying items with a constant rate of deterioration. Manufacturing defective items is permissible, and two levels of inspection are developed to control the imperfection. Developing a carbon cap-and-trade policy, Gao et al. [46] proposed a model for managing a multi-period inventory of raw materials when the items' demand is stochastic. Considering permissible partial backordering in an inventory model, Mishra et al. [47] extended a model for deteriorating items when deterioration can be controlled by preservation technology and carbon emissions can be controlled by green technology. They elaborated a constant deterioration rate and a price-dependent demand. Developing an inventory model for deteriorating items with expiration dates, Sarkar et al. [48] proposed imperfect quality items when the quality can be improved and carbon emissions are considered. Liu et al. [49] extended a coordinated model when carbon reduction is allowable and customers are eager to purchase items with lower emissions. Ullah et al. [50] investigated a sustainable strategy for remanufacturing when packaging is reusable, and the demand and returning items are stochastic. This investigation concludes 
that remanufacturing costs less than ordering and holding operations. A summary of the literature reviewed in this section that is most relevant to our paper is shown in Table 1.

Table 1. Literature review.

\begin{tabular}{|c|c|c|c|c|c|c|c|c|c|c|c|c|c|c|c|c|c|c|c|c|}
\hline \multirow[b]{2}{*}{ Paper } & \multicolumn{6}{|c|}{ Carbon Emission Policies } & \multicolumn{6}{|c|}{ Carbon Emission Causes } & \multicolumn{6}{|c|}{ Demand } & \multirow[b]{2}{*}{ 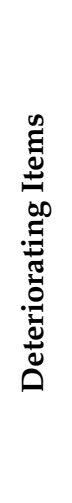 } & \multirow[b]{2}{*}{ 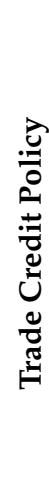 } \\
\hline & 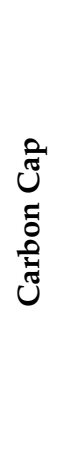 & 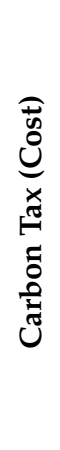 & 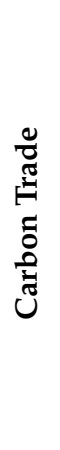 & 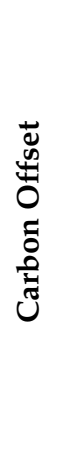 & 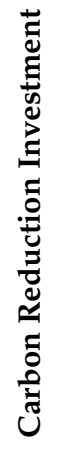 & 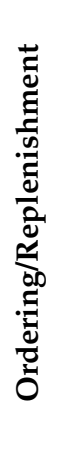 & 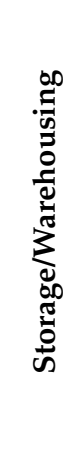 & 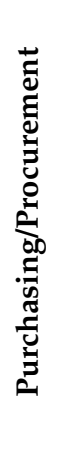 & 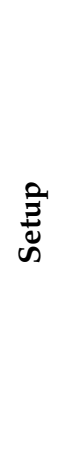 & 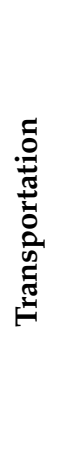 & 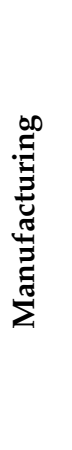 & 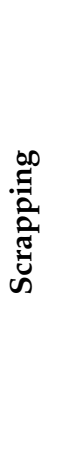 & 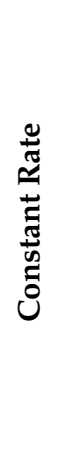 & 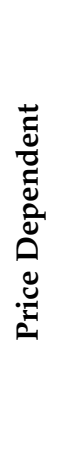 & 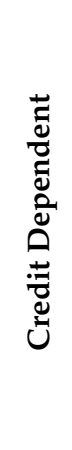 & 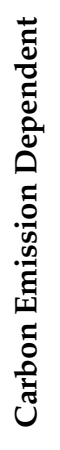 & 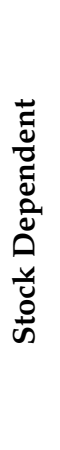 & 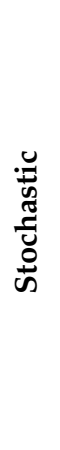 & & \\
\hline Hua et al. [4] & $\checkmark$ & & $\checkmark$ & & & $\checkmark$ & $\checkmark$ & & & & & & $\checkmark$ & & & & & & & \\
\hline Jaber et al. [34] & & $\checkmark$ & & & $\checkmark$ & & & & & & $\checkmark$ & & $\checkmark$ & & & & & & & \\
\hline Krass et al. [10] & & $\checkmark$ & & & $\checkmark$ & & & & & & $\checkmark$ & & & $\checkmark$ & & & & & & \\
\hline Toptal et al. [5] & $\checkmark$ & $\checkmark$ & $\checkmark$ & & $\checkmark$ & $\checkmark$ & $\checkmark$ & $\checkmark$ & & & & & $\checkmark$ & & & & & & & \\
\hline Wang et al. [19] & & & & & & & & & & & & & & & $\checkmark$ & & & & $\checkmark$ & $\checkmark$ \\
\hline Dye and Yang [35] & $\checkmark$ & & $\checkmark$ & $\checkmark$ & & $\checkmark$ & $\checkmark$ & $\checkmark$ & & & & & & & $\checkmark$ & & & & $\checkmark$ & $\checkmark$ \\
\hline Lou et al. [6] & $\checkmark$ & & $\checkmark$ & & $\checkmark$ & & & & & & $\checkmark$ & & & $\checkmark$ & & $\checkmark$ & & & & \\
\hline Qin et al. [43] & $\checkmark$ & & $\checkmark$ & & & $\checkmark$ & $\checkmark$ & $\checkmark$ & & & & & & & $\checkmark$ & $\checkmark$ & & & & $\checkmark$ \\
\hline Yang et al. [41] & $\checkmark$ & & $\checkmark$ & & $\checkmark$ & & & & & & $\checkmark$ & & & $\checkmark$ & & $\checkmark$ & & & & \\
\hline Chen and Sarker [20] & & & & & & & & & & & & & & $\checkmark$ & & & & & $\checkmark$ & \\
\hline Wu et al. [21] & & & & & & & & & & & & & $\checkmark$ & & & & & & $\checkmark$ & $\checkmark$ \\
\hline Bai et al.[11] & $\checkmark$ & & $\checkmark$ & & $\checkmark$ & & & & & & $\checkmark$ & & & $\checkmark$ & & & & & & \\
\hline Battini et al. [38] & $\checkmark$ & & $\checkmark$ & & $\checkmark$ & & $\checkmark$ & & & $\checkmark$ & & $\checkmark$ & $\checkmark$ & & & & & & & \\
\hline Tiwari et al. [9] & & & & & & & & & & & & & & $\checkmark$ & & & & & $\checkmark$ & $\checkmark$ \\
\hline Tiwari et al. [26] & & $\checkmark$ & & & & & $\checkmark$ & & & $\checkmark$ & & $\checkmark$ & $\checkmark$ & & & & & & $\checkmark$ & \\
\hline Aliabadi et al. [1] & & $\checkmark$ & & & & $\checkmark$ & $\checkmark$ & & & & & & & $\checkmark$ & $\checkmark$ & $\checkmark$ & & & $\checkmark$ & $\checkmark$ \\
\hline Bai et al. [42] & $\checkmark$ & & $\checkmark$ & & $\checkmark$ & & $\checkmark$ & & & & $\checkmark$ & & & $\checkmark$ & & & & & $\checkmark$ & \\
\hline Lu et al. [36] & $\checkmark$ & & $\checkmark$ & $\checkmark$ & $\checkmark$ & $\checkmark$ & $\checkmark$ & $\checkmark$ & $\checkmark$ & $\checkmark$ & $\checkmark$ & & $\checkmark$ & & & & & & $\checkmark$ & \\
\hline Mishra et al. [37] & $\checkmark$ & & $\checkmark$ & & $\checkmark$ & & $\checkmark$ & & $\checkmark$ & & & $\checkmark$ & $\checkmark$ & & & & & & & \\
\hline Mishra et al. [44] & $\checkmark$ & & $\checkmark$ & & $\checkmark$ & & & $\checkmark$ & & & & & & $\checkmark$ & & & $\checkmark$ & & $\checkmark$ & \\
\hline Shi et al. [24] & & $\checkmark$ & & & & & $\checkmark$ & $\checkmark$ & & $\checkmark$ & $\checkmark$ & & $\checkmark$ & & & & & & $\checkmark$ & $\checkmark$ \\
\hline Taleizadeh et al. [40] & & $\checkmark$ & & & & $\checkmark$ & $\checkmark$ & & & $\checkmark$ & & $\checkmark$ & & $\checkmark$ & & & & & & \\
\hline Gao et al. [46] & $\checkmark$ & & $\checkmark$ & & & & & & & $\checkmark$ & & & & & & & & $\checkmark$ & & \\
\hline Shaw et al. [45] & & $\checkmark$ & & & & & & & & $\checkmark$ & & & $\checkmark$ & & & & & & $\checkmark$ & \\
\hline Mishra et al. [47] & $\checkmark$ & $\checkmark$ & & & $\checkmark$ & $\checkmark$ & $\checkmark$ & $\checkmark$ & $\checkmark$ & & $\checkmark$ & $\checkmark$ & & $\checkmark$ & & & & & $\checkmark$ & \\
\hline Sarkar et al. [48] & & $\checkmark$ & & & & & & & & $\checkmark$ & & & $\checkmark$ & & & & & & $\checkmark$ & \\
\hline Liu et al. [49] & & $\checkmark$ & & & $\checkmark$ & & & $\checkmark$ & & & $\checkmark$ & & & & & $\checkmark$ & & & & \\
\hline This paper & $\checkmark$ & $\checkmark$ & & & $\checkmark$ & $\checkmark$ & $\checkmark$ & & & & & & & $\checkmark$ & & & & & $\checkmark$ & $\checkmark$ \\
\hline
\end{tabular}

According to the papers reviewed above, none of them have considered a deteriorating model and pricing and trade credit policy considering allowable carbon reduction investment. This paper's primary aim is to consider these challenges coincidently alongside highlighting the role of carbon cap and trade. This paper looks to obtain the optimal values for cycle length and selling price by using necessary and sufficient conditions for concavity and providing mathematical theorems for solution procedures. To validate the model, numerical experiments, sensitivity analyses, and managerial applications are presented. Finally, results from solving the mathematical model are discussed, and future insights are outlined. 


\section{Model Development}

\subsection{Problem Description}

To fill the abovementioned gap, an inventory model is developed for perishable items. In this system, items have their specific maximum lifetime, and the seller offers single-level trade credit to the buyer without prepayments. The demand function is a subtractive price-dependent function in that augmentation of the selling price leads to a decrease in demand. Ordering and holding operations cause carbon emissions, and the government rules cap and trade. Thus, the surplus emission allowance can be sold by the seller. Additionally, investing in carbon reduction technologies is allowable. The mathematical model is extended as follows.

\subsection{Notation}

A definition of symbols applicable in developing the mathematical model is provided in Table 2.

Table 2. Notation.

\begin{tabular}{|c|c|}
\hline \multicolumn{2}{|r|}{ Decision Variables } \\
\hline$p$ & selling price per unit (USD/unit) \\
\hline$T$ & seller's replenishment cycle time (years) \\
\hline G & carbon reduction technology investment (USD/year), where $G=0,1,2,3, \ldots$ \\
\hline \multicolumn{2}{|c|}{ Lot sizing parameters } \\
\hline$o$ & ordering cost per order (USD/cycle) \\
\hline$h$ & unit holding cost per unit per unit time (USD/unit/unit time) \\
\hline$S$ & allowable delay in the payment received from the buyer by the seller (years) \\
\hline$c$ & unit purchasing cost (USD/unit) \\
\hline$I_{e}$ & rate of interest earned (percentage) \\
\hline$m$ & maximum lifetime (expiry date) of the items (years) \\
\hline$I_{c}$ & rate of interest charged (percentage) \\
\hline \multicolumn{2}{|c|}{ Carbon emission parameters } \\
\hline$k_{1}$ & carbon emissions of ordering operations per cycle $(\mathrm{kg})$ \\
\hline$k_{2}$ & carbon emissions of holding operations per cycle $(\mathrm{kg})$ \\
\hline$x$ & efficiency of carbon reduction technology \\
\hline Z & carbon cap $(\mathrm{kg} /$ year $)$ \\
\hline$\xi$ & reduction fraction of carbon emissions after carbon reduction investment \\
\hline$\delta$ & carbon tax per cycle (USD/kg) \\
\hline \multicolumn{2}{|c|}{ Expressions and functions } \\
\hline$C E$ & carbon emissions per cycle (kg) \\
\hline$Q$ & order quantity of the seller (units) \\
\hline$D(p)$ & price-dependent demand rate \\
\hline$\theta(t)$ & deterioration rate as a time-varying function $(0 \leq \theta \leq 1)$ \\
\hline$I(t)$ & available inventory level at time $t$ \\
\hline$T P(T, p, G)$ & seller's annual total profit \\
\hline
\end{tabular}

In this paper, the replenishment cycle, selling price, and carbon reduction technology are considered variables. The replenishment cycle provides the ordering policy and determines how items will be replenished after the stock out. The selling price of items is a critical factor in marketing processes. This factor is considered as a variable using a price-dependent demand function. The optimal selling price leads the company to a pricing strategy to keep old customers and attract new ones. Carbon reduction technology investment is a crucial factor in reducing emissions in the whole inventory system. Along with sustainability considerations, investing in carbon reduction technology mitigates the costs associated with carbon emissions. 


\subsection{Assumptions}

1. Deteriorating items have their particular expiration dates $(m)$. Thus, when time is approaching $m$, the deterioration rate tends to 1 . The deterioration function is assumed as follows $[7,8,17,18]$.

$$
\theta(t)=\frac{1}{1+m-t} 0 \leq t \leq T \leq m
$$

2. The demand linearly decreases with increasing $p[8,15]$.

$$
D(p)=a-b p
$$

where $a$ and $b$ are positive constants. To ensure that the demand is non-negative, we have $0<p<\frac{a}{b}$.

3. The lead time is considered negligible. Shortages are not allowed to occur.

4. According to Hua et al. [4], carbon is emitted due to ordering and holding operations. Therefore, the carbon emissions $(C E)$ are formulated based on the holding units and replenishment of items. In addition, a carbon cap is defined so that if the carbon emissions do not exceed the carbon cap $Z$, the seller will accumulate revenue by selling the extra carbon allowance.

5. Due to reducing the carbon emissions and providing a greener inventory system, the seller decides to invest in advanced technology. The investment should not go higher than the budget on greening the inventory system. The fraction of average emission reduction is defined as $F=\xi\left(1-e^{-m G}\right)$. Therefore, we obtain $G=-\frac{\ln \left(1-\frac{F}{\xi}\right)}{m}[6,37]$. The fraction of carbon emission reduction $F$ is zero when $G=0$, and it tends to $\xi$ when $G \rightarrow \infty$. The carbon reduction investment function $F(G)$ is continuously differentiable with $F^{\prime}(G)>0$ and $F^{\prime \prime}(G)<0$.

The above assumptions are required to develop a sustainable inventory model and indicate that the inventory level is changing.

\section{Mathematical Model}

This section provides a novel sustainable economic order quantity (SEOQ) considering the carbon cap-and-trade policy for four potential cases. We discuss distinct SEOQ models when $T \leq S$ with and without carbon reduction investment (see Figure 1 ) and when $T \geq S$ with and without carbon reduction investment (see Figure 2).

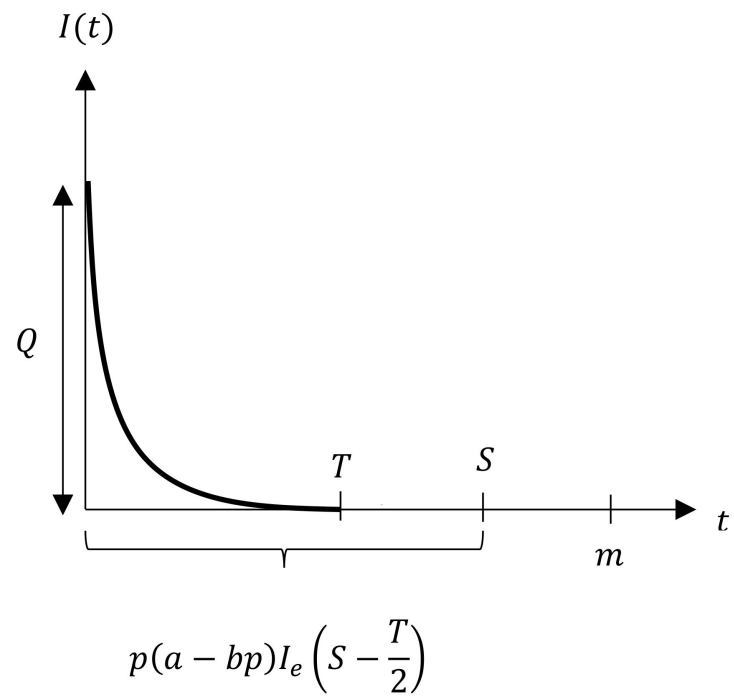

Figure 1. Inventory level for $(T \leq S)$. 


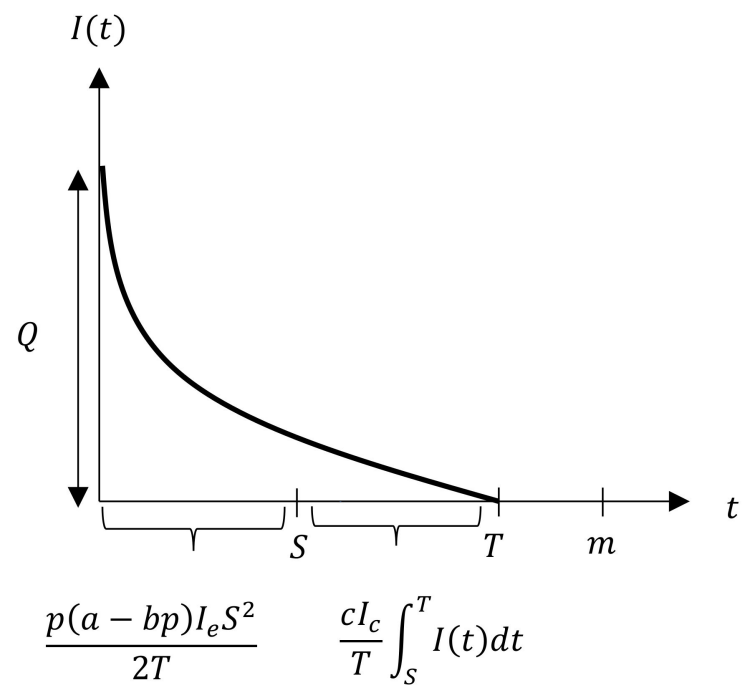

Figure 2. Inventory level when $(S \leq T)$.

4.1. Case 1: $(T \leq S)$ without Carbon Reduction Investment

The inventory is mitigated by demand for the items and perishing of the items during the cycle length $[0, T]$. Thus, it is formulated using differential equations as follows.

$$
\frac{d I(t)}{d t}=-D(p)-\theta(t) I(t) \quad 0 \leq t \leq T,
$$

Considering the boundary condition $I(T)=0$, and solving Equation (3), one can find

$$
I(t)=e^{-\delta(t)} \int_{t}^{T} e^{\delta(t)} D(n) d u,
$$

where

$$
\delta(t)=\int_{0}^{t} \theta(u) d u=\ln \left(\frac{1+m}{1+m-t}\right) .
$$

Substituting (5) into (4), the inventory level is obtained as

$$
\begin{gathered}
I(t)=\frac{1+m-t}{1+m} \int_{t}^{T} D(p) \frac{1+m}{1+m-u} d u=\frac{1+m-t}{1+m}(a-b p) \int_{t}^{T} \frac{1+m}{1+m-u} d u \\
=(1+m-t)(a-b p) \ln \left(\frac{1+m-t}{1+m-T}\right)
\end{gathered}
$$

Consequently, the supplier's order quantity is

$$
I(0)=Q=(a-b p)(1+m) \ln \left(\frac{1+m}{1+m-T}\right)
$$

Based on the above equations, the holding cost per cycle is

$$
\begin{gathered}
h \int_{0}^{T} I(t) d t=h(a-b p)\left[\int_{0}^{T}(1+m-t) \ln \left(\frac{1+m-t}{1+m-T}\right) d t\right] \\
\quad=h(a-b p)\left[\frac{(1+m)^{2}}{2} \ln \left(\frac{1+m}{1+m-T}\right)+\frac{T^{2}}{4}-\frac{(1+m) T}{2}\right]
\end{gathered}
$$

Referring particularly to Mishra et al. [37], the total carbon emissions (kg) linked to replenishment and holding the items are calculated by the following formula

$$
C E=\frac{k_{1}}{T}+k_{2} \frac{Q}{2}
$$


The above Equation (9) is applied to the model using an allowable carbon cap. When the supplier's carbon emission does not exceed the carbon cap, revenue is obtained from selling the surplus allowance for carbon emissions. The revenue obtained due to selling extra carbon emission allowance is found as follows $[6,36,37]$.

$$
\delta(Z-C E)=\delta\left(Z-\frac{k_{1}}{T}+k_{2} \frac{Q}{2}\right)
$$

In this subcase, all items are sold during the settlement, and the retailer accumulates interest at time $T$. The supplier charges no interest, and the interest accumulated per order during in time $S$ is obtained as

$$
\frac{p I_{e}}{T}\left[\int_{0}^{T} D(p) t d t+D(p) T(S-T)\right]=p(a-b p) I_{e}\left[S-\frac{T}{2}\right] .
$$

Finally, the seller's ordering cost per cycle is $o$, and the purchasing cost per cycle is $c I(0)$. Consequently, the supplier's annual total profit per unit of time is

$$
\begin{gathered}
T P(T, p)=\text { Net annual revenue - annual purchasing cost } \\
\text { - annual ordering cost - annual holding cost } \\
\text { +annual revenue due to carbon cap and trade } \\
\text { - annual interest charged + annual interest earned. }
\end{gathered}
$$

Then we have

$$
\begin{aligned}
T P_{1}(T, p)=p D(p) & -\frac{o}{T}-\frac{h}{T} D(p)\left[\frac{(1+m)^{2}}{2} \ln \left(\frac{1+m}{1+m-T}\right)+\frac{T^{2}}{4}-\frac{(1+m) T}{2}\right] \\
& -\frac{c I(0)}{T}+\delta(Z-C E)+p(a-b p) I_{e}\left[S-\frac{T}{2}\right] \\
& =p(a-b p)-\frac{o}{T}-\frac{h}{T}(a-b p)\left[\frac{(1+m)^{2}}{2} \ln \left(\frac{1+m}{1+m-T}\right)+\frac{T^{2}}{4}-\frac{(1+m) T}{2}\right]-\frac{c}{T}(a-b p) \\
& (1+m) \ln \left(\frac{1+m}{1+m-T}\right)+\delta\left\{Z-\left(\frac{k_{1}}{T}+\frac{k_{2}}{2}(a-b p)(1+m) \ln \left(\frac{1+m}{1+m-T}\right)\right)\right\} \\
& +p(a-b p) I_{e}\left[S-\frac{T}{2}\right] .
\end{aligned}
$$

\subsection{Case 2: $(S \leq T)$ without Carbon Redzuction Investment}

In this case, before the delay in payment period $S$, revenue can be accumulated by the retailer as

$$
\frac{p I_{e}}{T} \int_{0}^{S} D(p) t d t=\frac{p(a-b p) I_{e} S^{2}}{2 T} .
$$

However, the retailer cannot pay off by $S$ and should pay for all the sold items after $T-S$ at a charged rate of $I_{\mathcal{C}}$.

$$
\frac{c I_{c}}{T} \int_{S}^{T} I(t) d t=\frac{c I_{c}}{T}\left[\frac{(1+m-S)^{2}}{2} \ln \left(\frac{1+m-S}{1+m-T}\right)+\frac{(T-S)(T+S-1-m)}{4}\right] .
$$

Therefore, according to (12), the total profit obtained per year is

$$
\begin{aligned}
T P_{2}(T, p)= & p(a-b p)-\frac{o}{T}-\frac{h}{T}(a-b p)\left[\frac{(1+m)^{2}}{2} \ln \left(\frac{1+m}{1+m-T}\right)+\frac{T^{2}}{4}-\frac{(1+m) T}{2}\right] \\
& -\frac{c}{T}(a-b p)(1+m) \ln \left(\frac{1+m}{1+m-T}\right)+\delta\left\{Z-\left(\frac{k_{1}}{T}+\frac{k_{2}}{2}(a-b p)(1+m) \ln \left(\frac{1+m}{1+m-T}\right)\right)\right\} \\
& +\frac{p(a-b p) I_{e} S^{2}}{2 T}-\frac{c I_{c}}{T}\left[\frac{(1+m-S)^{2}}{2} \ln \left(\frac{1+m-S}{1+m-T}\right)+\frac{(T-S)(T+S-1-m)}{4}\right] .
\end{aligned}
$$

The seller's objective is to find the optimal cycle length $\left(T^{*}\right)$ and selling price $\left(p^{*}\right)$ of items in order to maximize the total profit obtained per year. 


\subsection{Case 3: $(T \leq S)$ with Carbon Reduction Investment}

The main difference between this case and the previous case discussed is a carbon emission reduction added to the total emissions, and a fixed carbon reduction investment is formulated as $\frac{G T}{T}=G$ [32]. Hence, the carbon emission function when carbon reduction investment is applied is formulated as

$$
\delta\left[Z-C E\left(1-\xi\left(1-e^{-m G}\right)\right)\right]=\left\{Z-\left(\frac{k_{1}}{T}+\frac{k_{2}}{2}(a-b p)(1+m) \ln \left(\frac{1+m}{1+m-T}\right)\right)\left(1-\xi\left(1-e^{-m G}\right)\right)\right\} .
$$

Therefore, the carbon reduction investment is added to the total profit function as a cost, and we have

$$
\begin{aligned}
T P_{3}(T, p, G)=p D & (p)-\frac{o}{T}-\frac{h}{T} D(p)\left[\frac{(1+m)^{2}}{2} \ln \left(\frac{1+m}{1+m-T}\right)+\frac{T^{2}}{4}-\frac{(1+m) T}{2}\right] \\
& -\frac{c I(0)}{T}-G+\delta\left[Z-C E\left(1-\xi\left(1-e^{-m G}\right)\right)\right]+p(a-b p) I_{e}\left[S-\frac{T}{2}\right] \\
& =p(a-b p)-\frac{o}{T}-\frac{h}{T}(a-b p)\left[\frac{(1+m)^{2}}{2} \ln \left(\frac{1+m}{1+m-T}\right)+\frac{T^{2}}{4}-\frac{(1+m) T}{2}\right]-\frac{c}{T}(a-b p) \\
& (1+m) \ln \left(\frac{1+m}{1+m-T}\right)-G \\
& +\delta\left\{Z-\left(\frac{k_{1}}{T}+\frac{k_{2}}{2}(a-b p)(1+m) \ln \left(\frac{1+m}{1+m-T}\right)\right)\left(1-\xi\left(1-e^{-m G}\right)\right)\right\} \\
& +p(a-b p) I_{e}\left[S-\frac{T}{2}\right] .
\end{aligned}
$$

\subsection{Case 4: $(S \leq T)$ with Carbon Reduction Investment}

Similar to case 2 and what we mentioned in case 3 , the total profit is

$$
\begin{aligned}
T P_{4}(T, p, G)=p D & (p)-\frac{o}{T}-\frac{h}{T} D(p)\left[\frac{(1+m)^{2}}{2} \ln \left(\frac{1+m}{1+m-T}\right)+\frac{T^{2}}{4}-\frac{(1+m) T}{2}\right] \\
& -\frac{c I(0)}{T}-G+\delta\left[C E\left(1-\xi\left(1-e^{-m G}\right)\right)\right]+\frac{p(a-b p) I_{e} S^{2}}{2 T} \\
& -\frac{c I_{C}}{T}\left[\frac{(1+m-S)^{2}}{2} \ln \left(\frac{1+m-S}{1+m-T}\right)+\frac{(T-S)(T+S-1-m)}{4}\right] \\
& =p(a-b p)-\frac{o}{T}-\frac{h}{T}(a-b p)\left[\frac{(1+m)^{2}}{2} \ln \left(\frac{1+m}{1+m-T}\right)+\frac{T^{2}}{4}-\frac{(1+m) T}{2}\right] \\
& -\frac{c}{T}(a-b p)(1+m) \ln \left(\frac{1+m}{1+m-T}\right)-G+\delta\left(\frac{k_{1}}{T}+\frac{k_{2}}{2}(a-b p)(1+m) \ln \left(\frac{1+m}{1+m-T}\right)\right)\left(1-\xi\left(1-e^{-m G}\right)\right) \\
& +\frac{p(a-b p) I_{e} S^{2}}{2 T}-\frac{c I_{C}}{T}\left[\frac{(1+m-S)^{2}}{2} \ln \left(\frac{1+m-S}{1+m-T}\right)+\frac{(T-S)(T+S-1-m)}{4}\right]
\end{aligned}
$$

In the next section, a procedure is employed to obtain the optimal cycle length and selling price values.

\section{Theoretical Results and Optimal Solution}

It is not possible to demonstrate that the profit function is concave using the second derivative. The theorem in Cambini and Martein [51] is applied, which states that the real-value function $q(x)$ is a (strictly) pseudo-concave function if $f(x)$ is a non-negative, differentiable and (strictly) concave, and $g(x)$ is positive, differentiable, and convex.

$$
q(x)=\frac{f(x)}{g(x)}
$$

Considering the results obtained from the above theorem, the following results are outlined.

$$
q_{1}(T, p)=\frac{T C_{1}(T, p)}{T}, q_{2}(T, p)=\frac{T C_{2}(T, p)}{T}
$$

and

$$
q_{3}(T, p, G)=\frac{T C_{3}(T, p, G)}{T}, \quad q_{4}(T, p, G)=\frac{T C_{4}(T, p, G)}{T}
$$




\subsection{Necessary Conditions for Optimal Solutions}

Theorem 1. $T P_{1}(T, p)$ is pseudo-concave concerning $T$ and $p$.

Proof. See Appendix A

Theorem 2. $T P_{2}(T, p)$ is pseudo-concave concerning $T$ and $p$.

Proof. See Appendix B.

Theorem 3. $T P_{3}(T, p, G)$ is pseudo-concave concerning $T$, $p$, and $G$.

Proof. See Appendix

Theorem 4. $T P_{4}(T, p, G)$ is pseudo-concave concerning $T, p$, and $G$.

Proof. See Appendix D.

\subsection{Sufficient Conditions for Optimal Solutions}

Theorem 5. The optimal solutions of $T$ and $p$ that maximize the total profit function $T P_{1}(T, p)$ are unique.

Proof. See Appendix E.

Theorem 6. The optimal solutions of $T$ and $p$ that maximize the total profit function $T P_{2}(T, p)$ are unique.

Proof. See Appendix F.

Theorem 7. The optimal solutions of $T$ and $p$ that maximize the total profit function $T_{3}(T, p, G)$ are unique.

Proof. See Appendix G.

Theorem 8. The optimal solutions of $T$ and $p$ that maximize the total profit function $T_{4}(T, p, G)$ are unique.

Proof. See Appendix H.

\section{Numerical Solution Approach}

To validate the problem using numerical examples, we first simplify the model. Simplification of the model is done using mathematical theorems to rewrite the model to provide a more comfortable solution using the numerical experiment as logarithm functions have made the derivatives complex. To solve the model, we used Mathematica software version 11.2 and implemented it on a PC with Intel Core i7 and CPU of $2.40 \mathrm{GHz}$ and 6 GB RAM to find the models' solutions and sensitivity analysis. To simplify the problem, we use the Maclaurin series for a natural logarithm, illustrated as follows.

$$
\ln (1+x)=\sum_{n=1}^{\infty}(-1)^{n+1} \frac{x^{n}}{n}=x-\frac{x^{2}}{2}+\frac{x^{3}}{3}-\ldots
$$


Therefore, the logarithm function of our elaboration is expanded as follows.

$$
\ln \left(\frac{1+m}{1+m-T}\right)=\left[m-\frac{m^{2}}{2}\right]-\left[(m-T)-\frac{1}{2}(m-T)^{2}\right]
$$

Using the abovementioned results, numerical examples for all cases are discussed.

\subsection{Example for Case $1(T \leq S)$ without Carbon Reduction Investment}

Consider $o=100 \$, h=0.5 \$, c=20 \$, a=100, b=2, m=0.7$ year, $S=0.5$ year, $k_{1}=1 \mathrm{~kg}, k_{2}=1 \mathrm{~kg}, \delta=5 \$ / \mathrm{kg}, Z=10 \mathrm{~kg} /$ year, and $I_{\mathcal{e}}=0.1$. Taking $\left\{\begin{array}{l}\frac{d q_{1}(T, p)}{d T}=0 \\ \frac{d q_{1}(T, p)}{d p}=0\end{array}\right.$ and computing in Mathematica 11.2, we have optimal values $T^{*}=0.379$ years and $p^{*}=33.444$ \$. Putting the optimal values in Equation (13) to get the optimal value of total profit, $T P_{1}^{*}(T, p)=338.341 \$$. The pseudo-concavity conditions are held by $\frac{d^{2} T P_{1}(T, p)}{d T^{2}}=-3989.95<0, \frac{d^{2} T P_{1}(T, p)}{d p^{2}}=-4.124<0$, and $\frac{d^{2} T P_{1}(T, p)}{d p d T}=42.435>0$. Therefore, the determinant of the corresponding Hessian matrix is $\left|H_{1}\right|=14,653.824>0$.

\subsection{Example for Case $2(T \geq S)$ without Carbon Reduction Investment}

Consider $o=100 \$, h=0.5 \$, c=20 \$, a=100, b=2, m=0.2$ year, $S=0.3$ year, $k_{1}=1 \mathrm{~kg}, k_{2}=1 \mathrm{~kg}, \delta=5 \$ / \mathrm{kg}, I_{c}=0.3, Z=10 \mathrm{~kg} /$ year, and $I_{e}=0.1$. Taking $\left\{\begin{array}{l}\frac{d q_{2}(T, p)}{d T}=0 \\ \frac{d q_{2}(T, p)}{d p}=0\end{array}\right.$ and computing in Mathematica 11.2, we have optimal values $T^{*}=0.518$ years and $p^{*}=38.492 \$$. Putting the optimal values in Equation (16) to get the optimal value of total profit, $T P_{2}^{*}(T, p)=112.141 \$$. The pseudo-concavity conditions are held by $\frac{d^{2} T P_{2}(T, p)}{d T^{2}}=-1522.59<0, \frac{d^{2} T P_{2}(T, p)}{d p^{2}}=-4.034<0$, and $\frac{d^{2} T P_{2}(T, p)}{d p d T}=33.424>0$. Therefore, the determinant of the corresponding Hessian matrix is $\left|H_{2}\right|=5025.976>0$.

\subsection{An Algorithm to Find the Optimal Solution for Case $3(T \leq S)$ with Carbon} Reduction Investment

Consider $o=100 \$, h=0.5 \$, c=20 \$, a=100, b=2, m=0.7$ year, $S=0.5$ year, $k_{1}=1 \mathrm{~kg}, k_{2}=1 \mathrm{~kg}, \delta=5 \$ / \mathrm{kg}, I_{c}=0.3, Z=10 \mathrm{~kg} /$ year, $\xi=0.2, x=0.8$, and $I_{\mathcal{e}}=0.1$. Then we use an algorithm to find the optimal solution of $G$.

- $\quad$ Step 1 Input the values of parameters.

- $\quad$ Step 2 Set $G=0$ and find the optimal variables $\left(T^{*}, p^{*}\right)$.

- $\quad$ Step 3 Substitute the optimal variables obtained into the total profit function and find the optimal total profit.

- $\quad$ Step 4 Set $G=0,1,2,3, \ldots$ and find the optimal solutions.

- Step 5 Continue the steps until the total profit function starts to decrease.

- Step 6 Introduce the optimal $G$ when the last increasing total profit function is illustrated.

- $\quad$ Step 7 Stop.

The results from the algorithm presented are provided in Table 3.

Table 3. Solution algorithm for case 3 to find $G^{*}$.

\begin{tabular}{cccc}
\hline \multicolumn{4}{c}{ Case 3 $(\boldsymbol{T} \leq \boldsymbol{S})$ with Carbon Reduction Investment } \\
\hline $\boldsymbol{G}^{*}$ & $\boldsymbol{T}^{*}$ & $\boldsymbol{p}^{*}$ & $\boldsymbol{T P}^{*}(\boldsymbol{T}, \boldsymbol{p}, \boldsymbol{G})$ \\
\hline 0 & 0.379 & 33.444 & 338.341 \\
1 & 0.380 & 33.416 & 341.678 \\
2 & 0.381 & 33.404 & 342.631 \\
3 & 0.381 & 33.398 & 342.509 \\
4 & 0.381 & 33.395 & 341.905 \\
\hline
\end{tabular}


The pseudo-concavity conditions are held by $\frac{d^{2} T P_{3}(T, p, G)}{d T^{2}}=-3877.07<0, \frac{d^{2} T P_{3}(T, p, G)}{d p^{2}}=$ $-4.123<0$, and $\frac{d^{2} T P_{3}(T, p, G)}{d p d T}=41.520>0$. Therefore, the determinant of the corresponding Hessian matrix is $\left|H_{2}\right|=14,261.249>0$.

\subsection{An Algorithm to Find the Optimal Solution for Case $4(T \geq S)$ with Green} Investment Technology

Consider $o=100 \$, h=0.5 \$, c=20 \$, a=100, b=2, m=0.2$ year, $S=0.3$ year, $k_{1}=1 \mathrm{~kg}, k_{2}=1 \mathrm{~kg}, \delta=5 \$ / \mathrm{kg}, I_{c}=0.3, Z=10 \mathrm{~kg} /$ year, $\xi=0.2, x=0.8$, and $I_{e}=0.1$. Then we use an algorithm to find the optimal solution of $G$.

- $\quad$ Step 1 Input the values of parameters.

- $\quad$ Step 2 Set $G=0$ and find the optimal variables $\left(T^{*}, p^{*}\right)$.

- $\quad$ Step 3 Substitute the optimal variables obtained into the total profit function and find the optimal total profit.

- $\quad$ Step 4 Set $G=0,1,2,3, \ldots$ and find the optimal solutions.

- $\quad$ Step 5 Continue the above steps until the total profit function starts to decrease.

- Step 6 Introduce the optimal $G$ when the last increasing total profit function is illustrated.

- $\quad$ Step 7 Stop.

The results from the algorithm presented are provided in Table 4.

Table 4. Solution algorithm for case 4 to find $G^{*}$.

\begin{tabular}{cccc}
\hline \multicolumn{4}{c}{ Case $4(\boldsymbol{S} \leq \boldsymbol{T})$ with Carbon Reduction Investment } \\
\hline $\boldsymbol{G}^{*}$ & $\boldsymbol{T}^{*}$ & $\boldsymbol{p}^{*}$ & $\boldsymbol{T P}^{*}(\boldsymbol{T}, \boldsymbol{p}, \boldsymbol{G})$ \\
\hline 0 & 0.518 & 38.492 & 112.141 \\
1 & 0.522 & 38.435 & 116.407 \\
2 & 0.524 & 38.410 & 117.792 \\
3 & 0.525 & 38.398 & 117.867 \\
4 & 0.526 & 38.393 & 117.350 \\
5 & 0.526 & 38.391 & 116.568 \\
\hline
\end{tabular}

The pseudo-concavity conditions are held by $\frac{d^{2} T P_{4}(T, p, G)}{d T^{2}}=-1440.89<0, \frac{d^{2} T P_{4}(T, p, G)}{d p^{2}}=$ $-4.034<0$, and $\frac{d^{2} T P_{4}(T, p, G)}{d p d T}=31.990>0$. Therefore, the determinant of the corresponding Hessian matrix is $\left|H_{2}\right|=4789.190>0$.

The concavity of different cases elaborated in this paper is shown in Figure 3.

\subsection{Sensitivity Analysis}

This subsection presents the sensitivity analysis for all cases in Tables 5 and 6 to illustrate how relevant inventory costs, demand function coefficients, and carbon emission parameters affect the optimal solution.

The behavior of parameters when changing their value is outlined to obtain the maximum total profit. The impacts of each parameter on the replenishment cycle and selling price, and the profit obtained, are discussed in Tables 5 and 6. Table 5 mainly concentrates on the cases that have not considered carbon reduction technology investment, and Table 6 discusses the cases that have considered carbon reduction technology investment. The impact of parameters is discussed when the profit function stands at its optimal point. Additionally, each parameter's significance in increasing or decreasing the amount of profit obtained can be derived from Tables 5 and 6. Therefore, the increasing or decreasing trend of the total profit is captured when each parameter's value increases. In the next section, managerial insights are proposed according to each parameter's impact on total profit. 


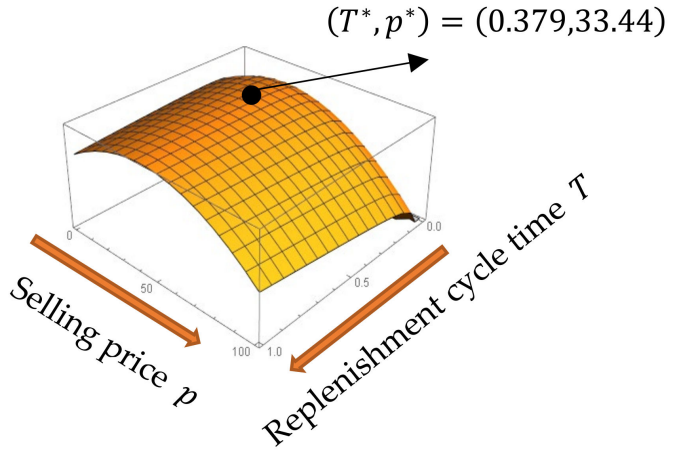

Concavity illustration of $T P_{1}(T, p)$.

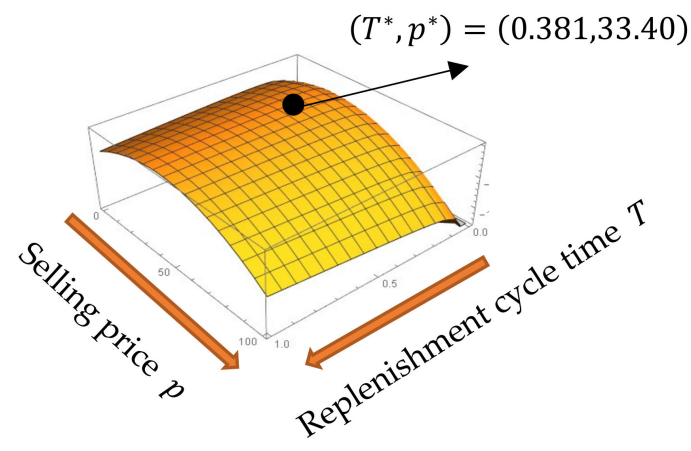

Concavity illustration of $T P_{3}(T, p)$.

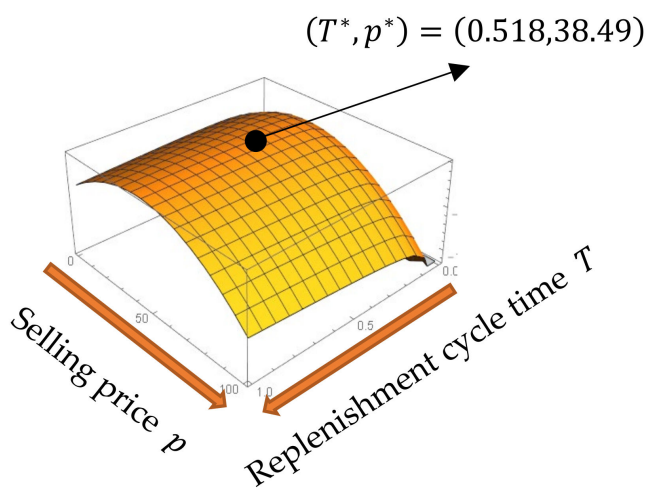

Concavity illustration of $T P_{2}(T, p)$

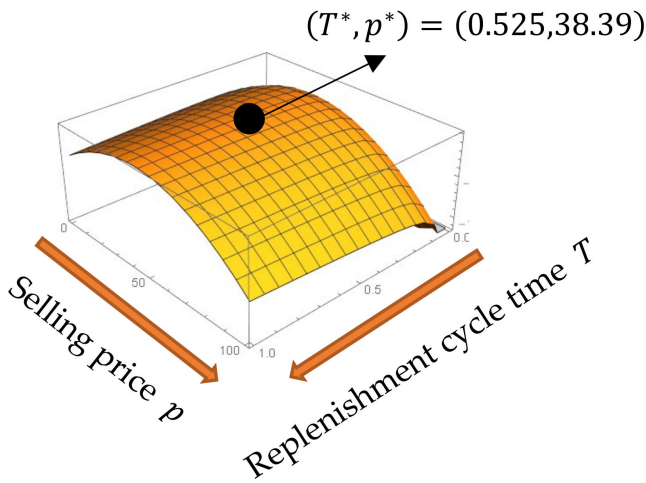

Concavity illustration of $T P_{4}(T, p)$.

Figure 3. Concavity illustration of different cases.

Table 5. Sensitivity analysis concerning the parameters for Cases 1 and 2.

\begin{tabular}{|c|c|c|c|c|c|c|}
\hline \multirow[t]{2}{*}{ Parameter } & \multicolumn{3}{|c|}{$\begin{array}{c}\text { Case } \\
\mathbf{1}(\boldsymbol{T} \leq S) \text { without Carbon Reduction Investment } \\
m=0.7 \text { and } S=0.5\end{array}$} & \multicolumn{3}{|c|}{$\begin{array}{c}\text { Case } \\
\mathbf{2}(S \leq T) \text { without Carbon Reduction Investmen } \\
m=0.2 \text { and } S=0.3\end{array}$} \\
\hline & $T^{*}$ & $p^{*}$ & $T P_{1}^{*}(T, p)$ & $T^{*}$ & $p^{*}$ & $T P_{2}^{*}(T, p)$ \\
\hline$o=80$ & 0.338 & 33.027 & 394.083 & 0.457 & 37.983 & 153.171 \\
\hline$o=100$ & 0.379 & 33.444 & 338.341 & 0.518 & 38.492 & 112.141 \\
\hline$o=120$ & 0.417 & 33.835 & 288.101 & 0.576 & 38.977 & 75.621 \\
\hline$h=0.5$ & 0.379 & 33.444 & 338.341 & 0.518 & 38.492 & 112.141 \\
\hline$h=1$ & 0.374 & 33.384 & 337.168 & 0.515 & 38.534 & 108.795 \\
\hline$h=1.5$ & 0.370 & 33.323 & 336.073 & 0.511 & 38.575 & 105.486 \\
\hline$c=15$ & 0.400 & 31.598 & 485.293 & 0.506 & 35.261 & 279.198 \\
\hline$c=17.5$ & 0.388 & 32.519 & 409.486 & 0.508 & 36.843 & 190.678 \\
\hline$c=20$ & 0.379 & 33.444 & 338.341 & 0.518 & 38.492 & 112.141 \\
\hline$a=100$ & 0.379 & 33.444 & 338.341 & 0.518 & 38.492 & 112.141 \\
\hline$a=110$ & 0.350 & 35.654 & 523.619 & 0.462 & 40.526 & 243.409 \\
\hline$a=120$ & 0.328 & 37.924 & 737.612 & 0.421 & 42.691 & 404.045 \\
\hline$b=1.5$ & 0.352 & 41.507 & 732.663 & 0.447 & 46.238 & 445.166 \\
\hline$b=1.75$ & 0.365 & 36.874 & 504.445 & 0.478 & 41.732 & 247.587 \\
\hline$b=2$ & 0.379 & 33.444 & 338.341 & 0.518 & 38.492 & 112.141 \\
\hline$k_{1}=0.5$ & 0.374 & 33.393 & 344.975 & 0.511 & 38.430 & 116.996 \\
\hline$k_{1}=1$ & 0.379 & 33.444 & 338.341 & 0.518 & 38.492 & 112.141 \\
\hline$k_{1}=1.5$ & 0.384 & 33.494 & 331.791 & 0.526 & 38.554 & 107.355 \\
\hline
\end{tabular}


Table 5. Cont.

\begin{tabular}{|c|c|c|c|c|c|c|}
\hline \multirow[t]{2}{*}{ Parameter } & \multicolumn{3}{|c|}{$\begin{array}{c}\text { Case } \\
\mathbf{1}(\boldsymbol{T} \leq S) \text { without Carbon Reduction Investment } \\
m=0.7 \text { and } S=0.5\end{array}$} & \multicolumn{3}{|c|}{$\begin{array}{c}\text { Case } \\
2(S \leq T) \text { without Carbon Reduction Investmen } \\
m=0.2 \text { and } S=0.3\end{array}$} \\
\hline & $T^{*}$ & $p^{*}$ & $T P_{1}^{*}(T, p)$ & $T^{*}$ & $p^{*}$ & $T P_{2}^{*}(T, p)$ \\
\hline$k_{2}=0.5$ & 0.391 & 33.367 & 351.719 & 0.547 & 38.294 & 131.917 \\
\hline$k_{2}=1$ & 0.379 & 33.444 & 338.341 & 0.518 & 38.492 & 112.141 \\
\hline$k_{2}=1.5$ & 0.368 & 33.520 & 325.558 & 0.495 & 38.687 & 93.867 \\
\hline$\delta=4$ & 0.381 & 33.393 & 336.227 & 0.526 & 38.389 & 111.746 \\
\hline$\delta=5$ & 0.379 & 33.444 & 338.341 & 0.518 & 38.492 & 112.141 \\
\hline$\delta=6$ & 0.376 & 33.495 & 340.500 & 0.511 & 38.596 & 112.709 \\
\hline$Z=9$ & 0.379 & 33.444 & 333.341 & 0.518 & 38.492 & 107.141 \\
\hline$Z=10$ & 0.379 & 33.444 & 338.341 & 0.518 & 38.492 & 112.141 \\
\hline$Z=11$ & 0.379 & 33.444 & 343.341 & 0.518 & 38.492 & 117.141 \\
\hline
\end{tabular}

Table 6. Sensitivity analysis for the parameters for Cases 3 and 4.

\begin{tabular}{|c|c|c|c|c|c|c|}
\hline \multirow[t]{2}{*}{ Parameter } & \multicolumn{3}{|c|}{$\begin{array}{c}\text { Case } 3(T \leq S) \text { with Carbon Reduction Investment } \\
\qquad m=0.7, S=0.5 \text {, and } G^{*}=2\end{array}$} & \multicolumn{3}{|c|}{$\begin{array}{c}\text { Case } 4(\boldsymbol{S} \leq \boldsymbol{T}) \text { with Carbon Reduction Investment } \\
\qquad m=0.2, S=0.3 \text {, and } G^{*}=3\end{array}$} \\
\hline & $T^{*}$ & $p^{*}$ & $T P_{3}^{*}(T, p, G)$ & $T^{*}$ & $p^{*}$ & $T P_{4}^{*}(T, p, G)$ \\
\hline$o=80$ & 0.346 & 32.837 & 398.108 & 0.462 & 37.900 & 158.377 \\
\hline$o=100$ & 0.381 & 33.404 & 342.631 & 0.525 & 38.398 & 117.867 \\
\hline$o=120$ & 0.419 & 33.793 & 292.687 & 0.585 & 38.871 & 81.846 \\
\hline$h=0.5$ & 0.381 & 33.404 & 344.631 & 0.525 & 38.398 & 117.867 \\
\hline$h=1$ & 0.376 & 33.344 & 343.429 & 0.521 & 38.440 & 114.445 \\
\hline$h=1.5$ & 0.371 & 33.283 & 342.305 & 0.517 & 38.482 & 111.064 \\
\hline$c=15$ & 0.403 & 31.559 & 490.313 & 0.516 & 35.179 & 286.686 \\
\hline$c=17.5$ & 0.390 & 32.479 & 414.113 & 0.517 & 36.757 & 197.255 \\
\hline$c=20$ & 0.381 & 33.404 & 342.631 & 0.525 & 38.398 & 117.867 \\
\hline$a=100$ & 0.381 & 33.404 & 342.631 & 0.525 & 38.398 & 117.867 \\
\hline$a=110$ & 0.352 & 35.617 & 528.288 & 0.468 & 40.448 & 249.972 \\
\hline$a=120$ & 0.330 & 37.891 & 742.621 & 0.427 & 42.624 & 411.315 \\
\hline$b=1.5$ & 0.354 & 41.471 & 737.242 & 0.454 & 46.166 & 451.921 \\
\hline$b=1.75$ & 0.367 & 36.836 & 505.888 & 0.485 & 41.652 & 253.873 \\
\hline$b=2$ & 0.381 & 33.404 & 342.631 & 0.525 & 38.398 & 117.867 \\
\hline$k_{1}=0.5$ & 0.377 & 33.361 & 348.171 & 0.519 & 38.349 & 121.781 \\
\hline$k_{1}=1$ & 0.381 & 33.404 & 342.631 & 0.525 & 38.398 & 117.867 \\
\hline$k_{1}=1.5$ & 0.385 & 33.445 & 337.152 & 0.531 & 38.448 & 113.998 \\
\hline$k_{2}=0.5$ & 0.391 & 33.339 & 353.949 & 0.550 & 38.237 & 134.351 \\
\hline$k_{2}=1$ & 0.381 & 33.404 & 342.631 & 0.525 & 38.398 & 117.867 \\
\hline$k_{2}=1.5$ & 0.372 & 33.467 & 331.750 & 0.504 & 38.558 & 102.466 \\
\hline$\delta=4$ & 0.383 & 33.361 & 339.289 & 0.532 & 38.315 & 115.851 \\
\hline$\delta=5$ & 0.381 & 33.404 & 342.631 & 0.525 & 38.398 & 117.867 \\
\hline$\delta=6$ & 0.379 & 33.446 & 346.008 & 0.519 & 38.483 & 120.009 \\
\hline$Z=9$ & 0.381 & 33.404 & 337.631 & 0.525 & 38.398 & 112.867 \\
\hline$Z=10$ & 0.381 & 33.404 & 342.631 & 0.525 & 38.398 & 117.867 \\
\hline$Z=11$ & 0.381 & 33.404 & 347.631 & 0.525 & 38.398 & 122.867 \\
\hline$\xi=0.1$ & 0.380 & 33.424 & 339.482 & 0.522 & 38.445 & 113.485 \\
\hline$\xi=0.2$ & 0.381 & 33.404 & 342.631 & 0.525 & 38.398 & 117.867 \\
\hline$\xi=0.3$ & 0.382 & 33.383 & 345.788 & 0.529 & 38.352 & 122.287 \\
\hline$x=0.7$ & 0.380 & 33.368 & 342.275 & 0.525 & 38.402 & 117.559 \\
\hline$x=0.8$ & 0.381 & 33.404 & 342.631 & 0.525 & 38.398 & 117.867 \\
\hline$x=0.9$ & 0.381 & 33.402 & 342.920 & 0.525 & 38.396 & 118.094 \\
\hline
\end{tabular}




\subsection{Managerial Applications}

As the impact of carbon emission reduction investment in the supply chain is discussed, a comparison between the cases in which the investment is allowable and the cases in which it is not allowable is proposed. Investing in green technology can lead to ameliorating the total profit of the seller in both cases when $T \leq S$ (See Figure 4) and $T>S$ (See Figure 5). In both cases, the total profit increases and reaches the highest point, which is the optimal point, and then decreases. Therefore, investing in green technology can enhance the total profit obtained.

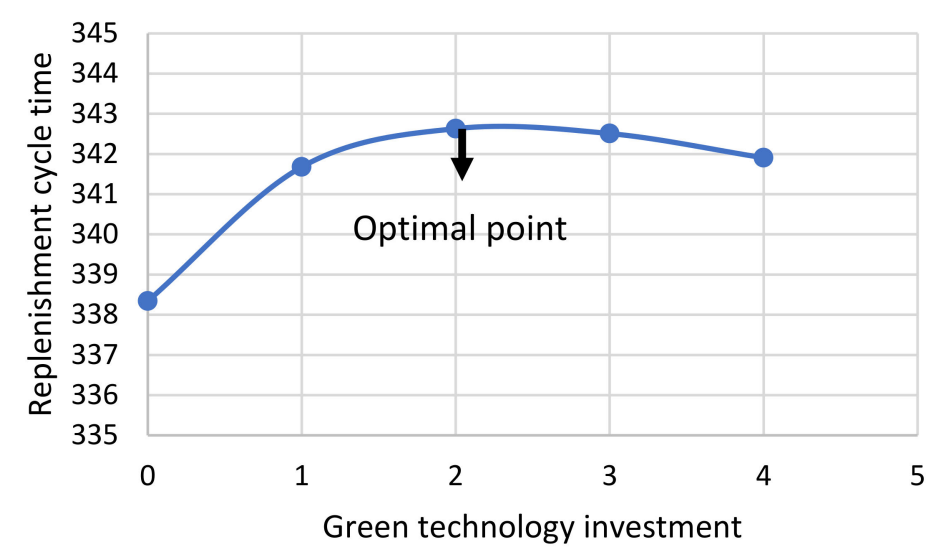

Figure 4. Impact of green technology investment on total profit when $T \leq S$.

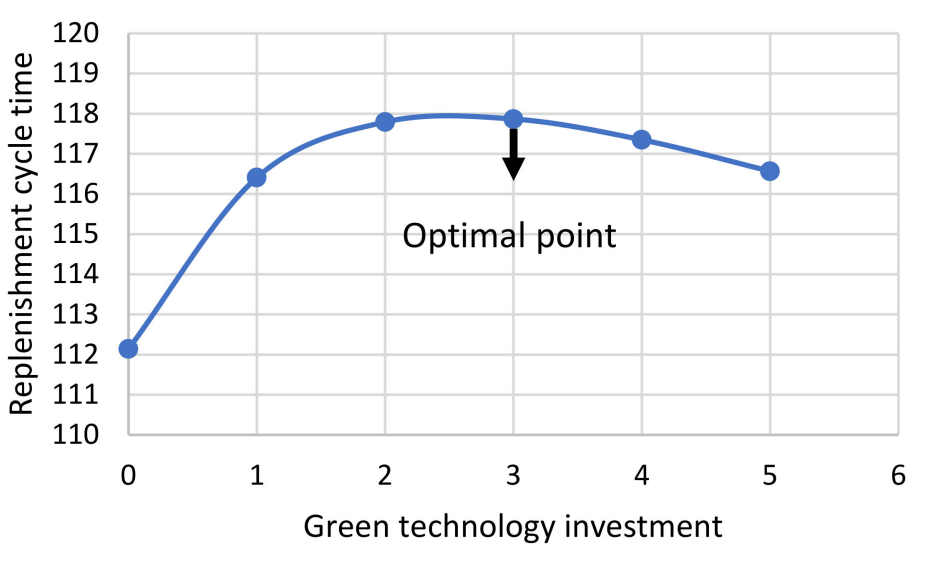

Figure 5. Impact of green technology investment on total profit when $T>S$.

Based on the parameters' behavior and their effects on the optimal solution in Tables 5 and 6, we can obtain the following managerial insights.

1. The increasing ordering $(o)$, holding $(h)$, and purchasing $(c)$ costs result in a decrease in the total profit. The reason for this circumstance is the increase in the relevant inventory costs. As ordering cost is an ongoing cost in the inventory system after the simplifications, an increase in ordering cost leads to the same decrease in total profit. The purchasing cost is directly connected to the order quantity, and when the unit purchasing cost increases, the retailer is forced to order the items in larger quantities, and the total purchasing cost will be increased. Moreover, as holding cost is related to the average inventory level, increasing the holding cost results in warehousing more extensive stocks, leading to an increase in total holding cost and a decrease in total profit. A trade-off between ordering, holding, and purchasing costs can result in achieving the maximum total profit. 
2. The increase in carbon emissions due to ordering $\left(k_{1}\right)$ and holding the inventory $\left(k_{2}\right)$ results in decreasing the total profit. A fixed tax is applied to the number of carbon emissions, and as the emissions increase, a higher carbon cost is imposed on the seller (see Figures 6 and 7). A solution to overcome this challenge is to invest more in carbon reduction technologies. As mentioned in Figures 7 and 8, a specific amount of green technology investment increases the total profit. Therefore, when the emissions due to ordering and warehousing processes increase, the seller can invest in green technology to avoid loss of profit.

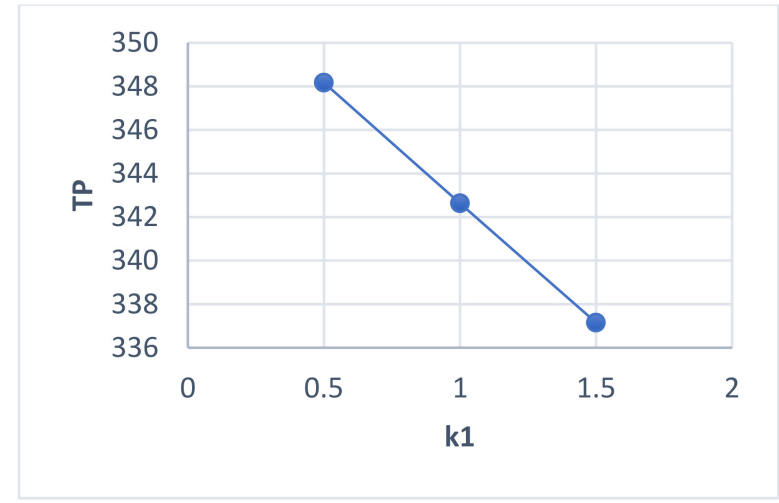

Figure 6. Impact of increasing $k_{1}$ on total profit.

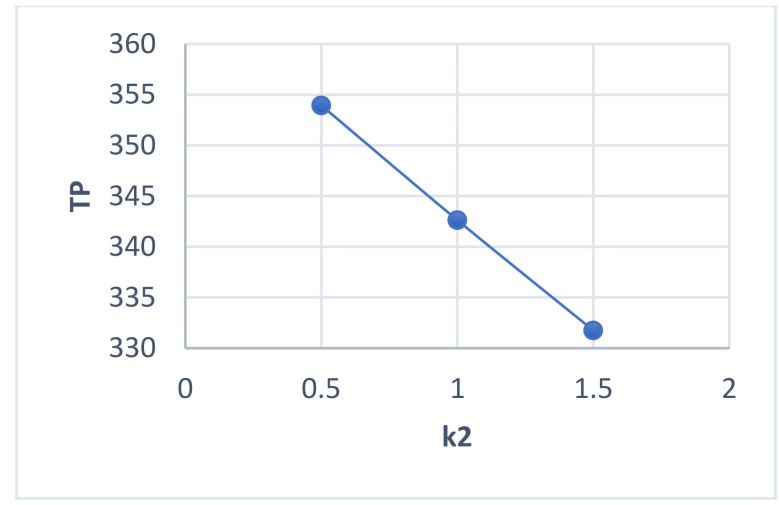

Figure 7. Impact of increasing $k_{2}$ on total profit.

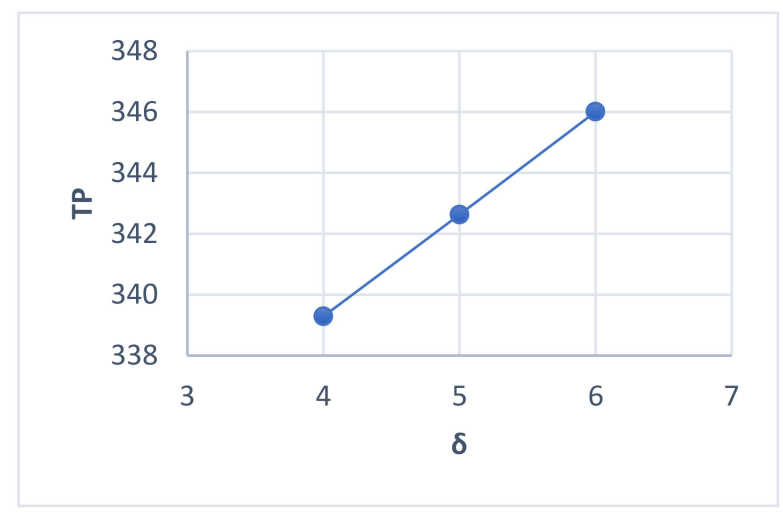

Figure 8. Impact of increasing $\delta$ on total profit.

3. The increasing carbon tax $\delta$ results in increasing the amount of total profit. As in all cases, the carbon emissions do not exceed the carbon cap. The seller can accumulate revenue by selling the surplus of carbon allowance at the rate of $\delta$ (see Figure 8). Analysis of the impact of the carbon tax on total profit is dependent on the emissions. 
When carbon emitted does not exceed the cap assigned, the allowance's surplus will benefit the seller, but when it exceeds the allowance, the seller should use different methods such as carbon reduction investment to mitigate profit losses.

4. An increase in carbon cap $Z$ can lead to increasing the total profit and increasing the carbon allowance that can be sold, and revenue can be obtained (see Figure 9). As the cap increases, the seller can sell a larger portion of allowance to other firms to accumulate revenue. In addition, more carbon is allowed to be emitted, which leads to an increase in the frequency of processes associated with emissions. Facilitating the processes can benefit the firms as well.

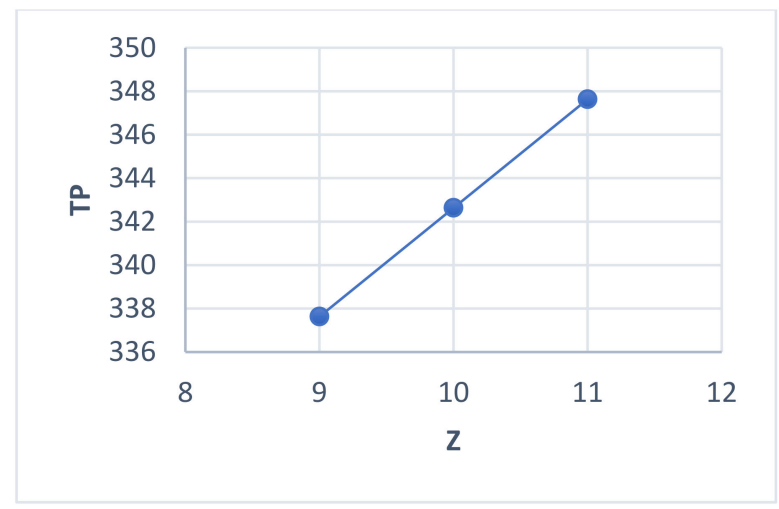

Figure 9. Impact of increasing $Z$ on total profit.

5. As the reduction fraction of carbon emissions after carbon reduction investment $\xi$ increases, the amount of carbon emissions decreases, and more revenue is gained due to selling the extra carbon emission allowance. Therefore, the total profit will be increased. Therefore, using technology and filters that reduce carbon emissions considerably is a practical application that can be analyzed in the market (see Figure 10).

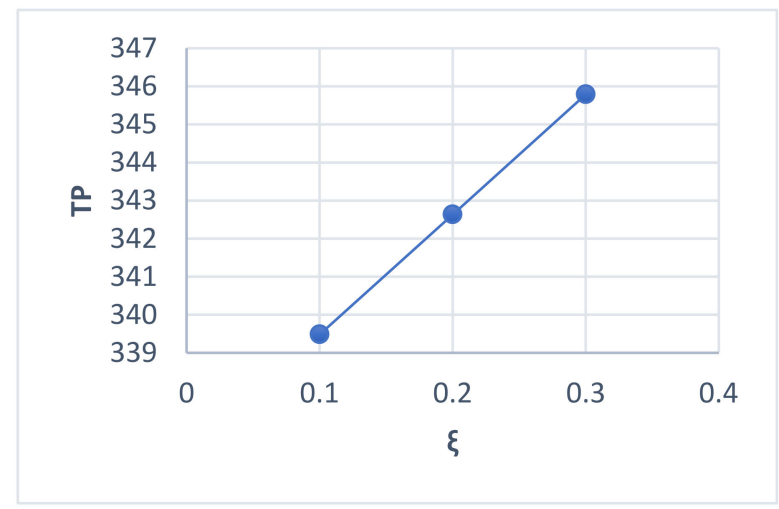

Figure 10. Impact of increasing $\xi$ on total profit.

6. Increasing the efficiency of carbon reduction results in increasing the total profit because the total carbon emissions will be reduced more efficiently, and the total profit will be obtained due to selling the extra carbon emission allowance. Therefore, filters that are more efficient in reducing carbon emissions can be utilized by firms.

\section{Conclusions}

With ever-increasing sustainability considerations in inventory systems, companies are looking for means to decrease emissions. One of the effective means is to invest in carbon emission reduction technologies to control emissions. Moreover, governments regulate deterrent and encouraging regulations to develop sustainability in supply chains. Deterioration of items is another challenge that companies confront. Most of the items 
deteriorate at a time-varying rate, and they have specific expiration dates. Therefore, companies are supposed to sell deteriorating items as soon as possible to avoid losses due to deterioration. Therefore, a permissible delay in payment is offered to the buyer instead of instant payment. The delay in payment stimulates the demand and increases the profit obtained in the long-term. Despite the significance of the abovementioned challenges, few papers have investigated the challenges of deterioration, delay in payment, and carbon emissions concurrently. Previous works in our contribution mainly concentrated on deteriorating items with a constant rate of deterioration considering carbon emissions. Very few papers developed a time-varying deterioration function and trade credit period. Almost no papers have elaborated carbon reduction investment technology for deteriorating items with a maximum lifetime to our knowledge. This paper concentrated on filling this gap by considering the integration of the mentioned issues. An EOQ model for deteriorating items with expiration dates is illustrated in this paper when a delay in payment is allowed. Carbon emissions due to ordering and warehousing operations are considered, and investing in carbon emission reduction technology is discussed in the case of carbon cap-and-tax regulation. The seller searches for the optimal value for replenishment cycle length and selling price when the carbon reduction investment is considered discrete. A solution algorithm is proposed, and necessary and sufficient conditions of optimality are discussed for validation.

The contribution's main novelty is applying carbon emission reduction technology to an inventory system for deteriorating items with expiration dates when a delay in payment is allowable. In addition, to highlight the pricing issue, a price-dependent demand function is developed. Discussing the impact of carbon reduction technology indicates the significance of efforts made to mitigate inventory system emissions. The results obtained from the quantitative experiment illustrate that a trade-off must be considered when investing in carbon reduction technologies to maximize the profit obtained along with eliminating emissions.

It is found that a trade-off must be considered between the investment in carbon emission reduction technologies and the profit obtained due to mitigating emissions. Increasing carbon tax leads to an increase in total profit. This can be considered a contradiction to previous works, but as carbon cap and tax is developed, the seller is encouraged to mitigate emissions and accumulate revenue by the carbon tax rate.

Possible opportunities to extend the mathematical model proposed in this paper are discussed as follows. The impact of other carbon emission regulations such as carbon offset and carbon trade can be discussed. Other sources of emissions include manufacturing, remanufacturing, recycling, scrapping, and transportation that have been discussed less frequently in recent papers. The deterioration rate can be considered stochastic to meet practical conditions. The Weibull distribution function is a common stochastic function that is utilized for indicating the rate of deterioration. The model can be extended for imperfect quality items. In this regard, scrap price, inspection, and allowable quality improvement can be developed. The demand function can depend on other factors such as trade credit, stock in hand, promotional efforts, and carbon emissions for developing a model in practice.

This paper's proposed model can be applied to food industries to mitigate emissions and avoid losses due to deterioration. Companies in developing countries with sustainability concerns can utilize the customized model for their governments' carbon emission policies.

Author Contributions: Conceptualization, A.S., U.M., M.-L.T. and B.S.; Formal analysis, A.S., M.L.T. and B.S.; Funding acquisition, B.S.; Investigation, U.M.; Supervision, U.M., M.-L.T. and B.S.; Validation, M.-L.T. and B.S.; Writing-Original draft, A.S.; Writing-Review \& editing, U.M., M.-L.T. and B.S. All authors have read and agreed to the published version of the manuscript.

Funding: This research received no external funding.

Institutional Review Board Statement: Not Applicable. 
Informed Consent Statement: Not Applicable.

Data Availability Statement: Not Applicable.

Conflicts of Interest: The authors declare no conflict of interest.

\section{Appendix A}

The first- and second-order partial derivatives of $q_{1}(T, p)$ with respect to $T$ are

$$
\begin{gathered}
\frac{d q_{1}(T, p)}{d T}=p(a-b p)-\frac{c(1+m)(a-b p)}{1+m-T}+I_{e} p(a-b p)\left(S-\frac{T}{2}\right) \\
-h(a-b p)\left(\frac{1}{2}(-1-m)+\frac{(1+m)^{2}}{2(1+m-T)}+\frac{T}{2}\right)-\frac{1}{2} I_{e} p(a-b p) T \\
-\left(\frac{k_{2}(1+m)(a-b p)}{2(1+m-T)}-\frac{k_{1}}{T^{2}}\right) T \delta-\delta\left[\frac{k_{1}}{T}+\frac{1}{2} k_{2}(1+m)(a-b p) \ln \left(\frac{1+m}{1+m-T}\right)\right]
\end{gathered}
$$

and

$$
\begin{gathered}
\frac{d^{2} q_{1}(T, p)}{d T^{2}}=-I_{e} p(a-b p)-h(a-b p)\left(\frac{1}{2}+\frac{(1+m)^{2}}{2(1+m-T)^{2}}\right)-\frac{c(1+m)(a-b p)}{(1+m-T)^{2}} \\
-2\left(\frac{k_{2}(1+m)(a-b p)}{2(1+m-T)}-\frac{k_{1}}{T^{2}}\right) \delta-\left(\frac{k_{2}(1+m)(a-b p)}{2(1+m-T)^{2}}+\frac{2 k_{1}}{T^{3}}\right) \delta T<0 .
\end{gathered}
$$

If $\frac{k_{1}}{k_{2}}<\frac{T^{2}(1+m)(a-b p)}{2(1+m-T)}$, according to (22), the total profit function $T P_{1}(T, p)$ is pseudoconcave with respect to $T$.

The first- and second-order partial derivatives of $q_{1}(T, p)$ with respect to $p$ are

$$
\begin{aligned}
& \frac{d q_{1}(T, p)}{d p}=-b p T+(a-b p) T-b I_{e} p T\left(S-\frac{T}{2}\right)+I_{e}(a-b p) T\left(S-\frac{T}{2}\right)+b c(1+m) \ln \left(\frac{1+m}{1+m-T}\right) \\
& +\frac{1}{2} b k_{2}(1+m) T \delta \ln \left(\frac{1+m}{1+m-T}\right)+b h\left(-\frac{1}{2}(1+m) T+\frac{T^{2}}{4}+\frac{1}{2}(1+m)^{2} \ln \left(\frac{1+m}{1+m-T}\right)\right) \\
& \text { and } \quad \frac{d^{2} q_{1}(T, p)}{d p^{2}}=-2 b T-2 b I_{e} T\left(S-\frac{T}{2}\right)<0 .
\end{aligned}
$$

Therefore, according to (22), the total profit function $T P_{1}(T, p)$ is pseudo-concave with respect to $p$.

\section{Appendix B}

The first- and second-order partial derivatives of $q_{2}(T, p)$ with respect to $T$ are

$$
\begin{gathered}
\frac{d q_{2}(T, p)}{d T}=p(a-b p)-\frac{c(1+m)(a-b p)}{1+m-T}-h(a-b p)\left(-\frac{1}{2}(1+m)+\frac{(1+m)^{2}}{2(1+m-T)}+\frac{T}{2}\right) \\
-c I_{\mathcal{C}}\left(\frac{(1+m-S)^{2}}{2(1+m-T)}+\frac{1}{4}(T-S)+\frac{1}{4}(-1-m+S+T)\right)-\left(\frac{k_{2}(1+m)(a-b p)}{2(1+m-T)}-\frac{k_{1}}{T^{2}}\right) T \delta \\
-\delta\left(\frac{k_{1}}{T}+\frac{1}{2} k_{2}(1+m)(a-b p) \ln \left(\frac{1+m}{1+m-T}\right)\right)
\end{gathered}
$$

and

$$
\begin{aligned}
\frac{d^{2} q_{2}(T, p)}{d T^{2}}= & -h(a-b p)\left(\frac{1}{2}+\frac{(1+m)^{2}}{2(1+m-T)^{2}}\right)-c I_{\mathcal{C}}\left(\frac{1}{2}+\frac{(1+m)^{2}}{2(1+m-T)^{2}}\right)-\frac{c(1+m)(a-b p)}{(1+m-T)^{2}} \\
& -2 \delta\left(\frac{k_{2}(1+m)(a-b p)}{2(1+m-T)}-\frac{k_{1}}{T^{2}}\right)-\left(\frac{k_{2}(1+m)(a-b p)}{2(1+m-T)^{2}}+\frac{2 k_{1}}{T^{3}}\right) \delta T<0
\end{aligned}
$$

If $\frac{k_{1}}{k_{2}}<\frac{T^{2}(1+m)(a-b p)}{2(1+m-T)}$, according to (22), the total profit function $T P_{2}(T, p)$ is pseudoconcave with respect to $T$. 
The first- and second-order partial derivatives of $q_{2}(T, p)$ with respect to $p$ are

$$
\begin{aligned}
& \frac{d q_{2}(T, p)}{d p}=-\frac{1}{2} b I_{e} p S^{2}+\frac{1}{2} I_{e}(a-b p) S^{2}-b p T+(a-b p) T+b c(1+m) \ln \left(\frac{1+m}{1+m-T}\right) \\
& +\frac{1}{2} b k_{2}(1+m) T \delta \ln \left(\frac{1+m}{1+m-T}\right)+b h\left(-\frac{1}{2}(1+m) T+\frac{T^{2}}{4}+\frac{1}{2}(1+m)^{2} \ln \left(\frac{1+m}{1+m-T}\right)\right)
\end{aligned}
$$

and

$$
\frac{d^{2} q_{2}(T, p)}{d p^{2}}=-b I_{e} S^{2}-2 b T<0
$$

Therefore, according to (22), the total profit function $T P_{2}(T, p)$ is pseudo-concave with respect to $p$.

\section{Appendix C}

The first- and second-order partial derivatives of $q_{3}(T, p, G)$ with respect to $T$ are

$$
\begin{gathered}
\frac{d q_{3}(T, p, G)}{d T}=p(a-b p)-\frac{c(1+m)(a-b p)}{1+m-T}+I_{e} p(a-b p)\left(S-\frac{T}{2}\right) \\
-h(a-b p)\left(\frac{1}{2}(-1-m)+\frac{(1+m)^{2}}{2(1+m-T)}+\frac{T}{2}\right)-\frac{1}{2} I_{e} p(a-b p) T \\
-\left(\frac{k_{2}(1+m)(a-b p)}{2(1+m-T)}-\frac{k_{1}}{T^{2}}\right) T \delta\left(1-\xi\left(1-e^{-x G}\right)\right) \\
+\delta\left(Z-\left(1-\xi\left(1-e^{-x G}\right)\right)\right)\left[\frac{k_{1}}{T}+\frac{1}{2} k_{2}(1+m)(a-b p) \ln \left(\frac{1+m}{1+m-T}\right)\right]
\end{gathered}
$$

and

$$
\begin{aligned}
\frac{d^{2} q_{3}(T, p, G)}{d T^{2}}= & -I_{e} p(a-b p)-h(a-b p)\left(\frac{1}{2}+\frac{(1+m)^{2}}{2(1+m-T)^{2}}\right)-\frac{c(1+m)(a-b p)}{(1+m-T)^{2}} \\
& -2\left(\frac{k_{2}(1+m)(a-b p)}{2(1+m-T)}-\frac{k_{1}}{T^{2}}\right) \delta\left(1-\xi\left(1-e^{-x G}\right)\right) \\
- & \left(\frac{k_{2}(1+m)(a-b p)}{2(1+m-T)^{2}}+\frac{2 k_{1}}{T^{3}}\right) \delta T\left(1-\xi\left(1-e^{-x G}\right)\right)<0 .
\end{aligned}
$$

If $\frac{k_{1}}{k_{2}}<\frac{T^{2}(1+m)(a-b p)}{2(1+m-T)}$, according to (23), the total profit function $T P_{3}(T, p, G)$ is pseudoconcave with respect to $T$.

The first- and second-order partial derivatives of $q_{3}(T, p, G)$ with respect to $p$ are

$$
\begin{aligned}
\frac{d q_{3}(T, p, G)}{d p}=-b p T+( & a-b p) T-b I_{e} p T\left(S-\frac{T}{2}\right)+I_{e}(a-b p) T\left(S-\frac{T}{2}\right)+b c(1+m) \ln \left(\frac{1+m}{1+m-T}\right) \\
& +\frac{1}{2} b k_{2}\left(1-\xi\left(1-e^{-x G}\right)\right)(1+m) T \delta \ln \left(\frac{1+m}{1+m-T}\right) \\
& +b h\left(-\frac{1}{2}(1+m) T+\frac{T^{2}}{4}+\frac{1}{2}(1+m)^{2} \ln \left(\frac{1+m}{1+m-T}\right)\right)
\end{aligned}
$$

and

$$
\frac{d^{2} q_{3}(T, p, G)}{d p^{2}}=-2 b T-2 b I_{e} T\left(S-\frac{T}{2}\right)<0 .
$$

Therefore, according to (23), the total profit function $T P_{3}(T, p, G)$ is pseudo-concave with respect to $p$.

The first- and second-order partial derivatives of $q_{3}(T, p, G)$ with respect to $p$ are

$$
\frac{d^{2} q_{3}(T, p, G)}{d G}=-1+e^{-G x} T \delta x \xi\left(\frac{k_{1}}{T}+\frac{k_{2}(1+m)(a-b p)}{2} \ln \left(\frac{1+m}{1+m-T}\right)\right) .
$$

and

$$
\frac{d^{2} q_{3}(T, p, G)}{d G^{2}}=-e^{-G x} T \delta x^{2} \xi\left(\frac{k_{1}}{T}+\frac{k_{2}(1+m)(a-b p)}{2} \ln \left(\frac{1+m}{1+m-T}\right)\right)<0 .
$$


Therefore, according to (23), the total profit function $T P_{3}(T, p, G)$ is pseudo-concave with respect to $G$.

\section{Appendix D}

The first- and second-order partial derivatives of $q_{4}(T, p, G)$ with respect to $T$ are

$$
\begin{aligned}
& \frac{d q_{4}(T, p, G)}{d T}=p(a-b p)-\frac{c(1+m)(a-b p)}{1+m-T}-h(a-b p)\left(-\frac{1}{2}(1+m)+\frac{(1+m)^{2}}{2(1+m-T)}+\frac{T}{2}\right) \\
& -c I_{\mathcal{C}}\left(\frac{(1+m-S)^{2}}{2(1+m-T)}+\frac{1}{4}(T-S)+\frac{1}{4}(-1-m+S+T)\right) \\
& -\left(\frac{k_{2}(1+m)(a-b p)}{2(1+m-T)}-\frac{k_{1}}{T^{2}}\right)\left(1-\xi\left(1-e^{-x G}\right)\right) T \delta \\
& +\delta\left(Z-\left(1-\xi\left(1-e^{-x G}\right)\right)\right)\left(\frac{k_{1}}{T}+\frac{1}{2} k_{2}(1+m)(a-b p) \ln \left(\frac{1+m}{1+m-T}\right)\right) \\
& \frac{d^{2} q_{4}(T, p, G)}{d T^{2}}=-h(a-b p)\left(\frac{1}{2}+\frac{(1+m)^{2}}{2(1+m-T)^{2}}\right)-c I_{\mathcal{C}}\left(\frac{1}{2}+\frac{(1+m)^{2}}{2(1+m-T)^{2}}\right)-\frac{c(1+m)(a-b p)}{(1+m-T)^{2}} \\
& -2 \delta\left(1-\xi\left(1-e^{-x G}\right)\left(\frac{k_{2}(1+m)(a-b p)}{2(1+m-T)}-\frac{k_{1}}{T^{2}}\right)\right. \\
& -\left(\frac{k_{2}(1+m)(a-b p)}{2(1+m-T)^{2}}+\frac{2 k_{1}}{T^{3}}\right) \delta T\left(1-\xi\left(1-e^{-x G}\right)<0\right.
\end{aligned}
$$

If $\frac{k_{1}}{k_{2}}<\frac{T^{2}(1+m)(a-b p)}{2(1+m-T)}$, according to (23), the total profit function $T C_{4}(T, p, G)$ is pseudoconcave with respect to $T$.

The first- and second-order partial derivatives of $q_{4}(T, p, G)$ with respect to $p$ are

$$
\begin{aligned}
\frac{d q_{4}(T, p, G)}{d p}=-\frac{1}{2} b I_{e} p S^{2}+\frac{1}{2} I_{e}(a-b p) S^{2}-b p T+(a-b p) T+b c(1+m) \ln \left(\frac{1+m}{1+m-T}\right) \\
+\frac{1}{2} b k_{2}(1+m) T \delta\left(1-\xi\left(1-e^{-x G}\right)\right) \ln \left(\frac{1+m}{1+m-T}\right) \\
+b h\left(-\frac{1}{2}(1+m) T+\frac{T^{2}}{4}+\frac{1}{2}(1+m)^{2} \ln \left(\frac{1+m}{1+m-T}\right)\right)
\end{aligned}
$$

and

$$
\frac{d^{2} q_{4}(T, p, G)}{d p^{2}}=-b I_{e} S^{2}-2 b T<0
$$

Therefore, according to (23), the total profit function $T P_{4}(T, p, G)$ is pseudo-concave with respect to $p$.

The first- and second-order partial derivatives of $q_{4}(T, p, G)$ with respect to $G$ are

$$
\frac{d^{2} q_{3}(T, p, G)}{d G}=-1+e^{-G x} T \delta x \xi\left(\frac{k_{1}}{T}+\frac{k_{2}(1+m)(a-b p)}{2} \ln \left(\frac{1+m}{1+m-T}\right)\right) .
$$

and

$$
\frac{d^{2} q_{3}(T, p, G)}{d G^{2}}=-e^{-G x} T \delta x^{2} \xi\left(\frac{k_{1}}{T}+\frac{k_{2}(1+m)(a-b p)}{2} \ln \left(\frac{1+m}{1+m-T}\right)\right)<0 .
$$

Therefore, according to (23), the total profit function $T P_{4}(T, p, G)$ is pseudo-concave with respect to $G$.

\section{Appendix E}

The condition of optimality is that the Hessian matrix of $q_{1}(T, p)$ is positive definite, i.e., all eigenvalues of the Hessian matrix $H_{1}=\left[\begin{array}{ll}\frac{d^{2} q_{1}(T, p)}{d T^{2}} & \frac{d^{2} q_{1}(T, p)}{d T d p} \\ \frac{d^{2} q_{1}(T, p)}{d T d p} & \frac{d^{2} q_{1}(T, p)}{d p^{2}}\end{array}\right]$ are negative definite, where $\frac{d^{2} q_{1}(T, p)}{d T^{2}}<0$ and $\frac{d^{2} q_{1}(T, p)}{d p^{2}}<0$ as per the proofs in Appendix A. Addi- 


$$
\begin{aligned}
& \text { tionally, the determinant of the Hessian matrix }\left|H_{1}\right|=\left|\begin{array}{l}
\frac{d^{2} q_{1}(T, p)}{d T^{2}} \quad \frac{d^{2} q_{1}(T, p)}{d T d p} \\
\frac{d^{2} q_{1}(T, p)}{d T d p} \quad \frac{d^{2} q_{1}(T, p)}{d p^{2}}
\end{array}\right| \begin{array}{l}
T=T^{*}, p=p^{*} \\
=
\end{array} \\
& \begin{array}{c}
\frac{1}{4(1+m-T)^{2}}\left\{2 b ( a - b p ) T ( - 2 + I _ { e } ( T - 2 S ) ) \left[\left(2 c-k_{2} \delta T\right)(1+m)+\left(2 p I_{e}+2 h\right)(1+m-T)^{2}\right.\right. \\
\left.+2 k_{2} \delta(1+m)^{2}\right]+\left[(1+m-T)(2 a+T h-4 b p)\left(1+I_{e}(S-T)\right)+(1+m)\left(2 b c+T k_{2} \delta+\right.\right. \\
\left.\left.T h+b k_{2} \delta(1+m-T) \ln \left(\frac{1+m}{1+m-T}\right)\right]^{2}\right\}>0 \text { for any positive value of } T \text { and } p, \text { where }
\end{array} \\
& \left\{\begin{array}{c}
T b(a-b p) T\left(-2+I_{e}(T-2 S)\right)\left[\left(2 c-k_{2} \delta T\right)(1+m)+\left(2 p I_{e}+2 h\right)(1+m-T)^{2}+2 k_{2} \delta(1+m)^{2}\right] \\
+\left[(1+m-T)(2 a+T h-4 b p)\left(1+I_{e}(S-T)\right)+(1+m)\left(2 b c+T k_{2} \delta+T h\right.\right. \\
\left.\left.+b k_{2} \delta(1+m-T) \ln \left(\frac{1+m}{1+m-T}\right)\right]^{2}\right\}>0
\end{array}\right.
\end{aligned}
$$

Considering the above condition, according to (22), the optimal values are unique, and the total profit function is maximized at $T=T^{*}, p=p^{*}$.

\section{Appendix F}

The condition of optimality is that the Hessian matrix of $q_{2}(T, p)$ is positive definite, i.e., all eigenvalues of the Hessian matrix $H_{1}=\left[\begin{array}{cc}\frac{d^{2} q_{2}(T, p)}{d T^{2}} & \frac{d^{2} q_{2}(T, p)}{d T d p} \\ \frac{d^{2} q_{2}(T, p)}{d T d p} & \frac{d^{2} q_{2}(T, p)}{d p^{2}}\end{array}\right]$ are negative definite, where $\frac{d^{2} q_{2}(T, p)}{d T^{2}}<0$ and $\frac{d^{2} q_{2}(T, p)}{d p^{2}}<0$ according to the proofs in Appendix B. Additionally, the determinant of the Hessian matrix $\left|H_{2}\right|=\left[\begin{array}{cc}\frac{d^{2} q_{2}(T, p)}{d T^{2}} & \frac{d^{2} q_{2}(T, p)}{d T d p} \\ \frac{d^{2} q_{2}(T, p)}{d T d p} & \frac{d^{2} q_{2}(T, p)}{d p^{2}}\end{array}\right]_{T=T^{*}, p=p^{*}}=$ $\frac{1}{4(1+m-T)^{2} T^{2}}\left\{(1+m-T)^{2} T^{2}\left[h(a-b p)+c I_{c}\right]+(1+m)(a-b p) T^{2}\left[2 c+2(1+m-T) k_{2} \delta\right.\right.$ $\left.+k_{2} \delta T+h(1+m)+c I_{c} T^{2}(1+m-S)^{2}\right]-T^{2}\left[(1+m)\left[2 b c+b k_{2} T \delta+b h T(1+m-T)\right.\right.$ $\left.\left.\left.\ln \left(\frac{1+m}{1+m-T}\right)\right]+(1+m-T)[2 a-4 b p+b h T]\right]^{2}\right\}>0$ for any positive value of $T$ and $p$, where

$$
\begin{gathered}
\left\{(1+m-T)^{2} T^{2}\left[h(a-b p)+c I_{c}\right]\right. \\
+(1+m)(a-b p) T^{2}\left[2 c+2(1+m-T) k_{2} \delta+k_{2} \delta T+h(1+m)+c I_{c} T^{2}(1+m-S)^{2}\right] \\
\left.-T^{2}\left[(1+m)\left[2 b c+b k_{2} T \delta+b h T(1+m-T) \ln \left(\frac{1+m}{1+m-T}\right)\right]+(1+m-T)[2 a-4 b p+b h T]\right]^{2}\right\}>0
\end{gathered}
$$

Considering the above condition, according to (22), the optimal values are unique, and the total profit function is maximized at $T=T^{*}, p=p^{*}$.

\section{Appendix G}

The condition of optimality is that the Hessian matrix of $q_{3}(T, p, G)$ is positive definite, i.e., all eigenvalues of the Hessian matrix $H_{3}=\left[\begin{array}{ccc}\frac{d^{2} q_{3}(T, p, G)}{d T^{2}} & \frac{d^{2} q_{3}(T, p, G)}{d T d p} & \frac{d^{2} q_{3}(T, p, G)}{d T d G} \\ \frac{d^{2} q_{3}(T, p, G)}{d p d T} & \frac{d^{2} q_{3}(T, p, G)}{d p^{2}} & \frac{d^{2} q_{3}(T, p, G)}{d p d G} \\ \frac{d^{2} q_{3}(T, p, G)}{d G d T} & \frac{d^{2} q_{3}(T, p, G)}{d G d p} & \frac{d^{2} q_{3}(T, p, G)}{d G^{2}}\end{array}\right]$ are negative definite, where $\frac{d^{2} q_{2}(T, p, G)}{d T^{2}}<0, \frac{d^{2} q_{2}(T, p, G)}{d p^{2}}<0$, and $\frac{d^{2} q_{3}(T, p, G)}{d G^{2}}<0$ as per the proofs in Appendix C. Additionally, the determinant of the Hessian matrix 
$\left|H_{3}\right|=\left|\begin{array}{lll}\frac{d^{2} q_{3}(T, p, G)}{d T^{2}} & \frac{d^{2} q_{3}(T, p, G)}{d T d p} & \frac{d^{2} q_{3}(T, p, G)}{d T d G} \\ \frac{d^{2} q_{3}(T, p, G)}{d p d T} & \frac{d^{2} q_{3}(T, p, G)}{d p^{2}} & \frac{d^{2} q_{3}(T, p, G)}{d p d G} \\ \frac{d^{2} q_{3}(T, p, G)}{d G d T} & \frac{d^{2} q_{3}(T, p, G)}{d G d p} & \frac{d^{2} q_{3}(T, p, G)}{d G^{2}}\end{array}\right|_{T=T^{*}, p=p^{*}, G=G^{*}}=\frac{e^{-2 G x} x^{2} \delta \xi}{8(1+m-T)^{2} T}\left\{\left[k_{2}{ }^{2}(1+m)^{2}\right.\right.$

$\left.T \delta \xi\left(\ln \left(\frac{1+m}{1+m-T}\right)\right)^{2}-2 b e^{-G x}\left(2+I_{e}(2 S-T)\right)\left(2 k_{1}+k_{2}(1+m)(a-b p) T\left(\ln \left(\frac{1+m}{1+m-T}\right)\right)\right)\right]$

$\left[(1+m)(a-b p) T^{2}\left(2 c+h(1+m)+\delta\left(1+\xi\left(-1+e^{-G x}\right)\left(k_{2} T(1+m)-k_{2}\right)\right]+2 b k_{2}{ }^{2}\right.\right.$

$(1+m)^{2}(a-b p)^{2} T^{2} \delta \xi\left(2+I_{e}(2 S-T)\right)\left(T+(1+m-T) \ln \left(\frac{1+m}{1+m-T}\right)\right)^{2}-2 b k_{2}{ }^{2}(1+m)^{2}$

$(a-b p) T^{2} \delta \xi\left(\ln \left(\frac{1+m}{1+m-T}\right)\right)\left(T+(1+m-T)\left(\ln \left(\frac{1+m}{1+m-T}\right)\right)\right)\left[(1+m)\left(2 b c+b h T+b k_{2} \delta\right.\right.$

$\left(1+\xi\left(-1+e^{-G x}\right)\left(T+(1+m-T)\left(\ln \left(\frac{1+m}{1+m-T}\right)\right)\right)\right)+(1+m-T)(2 a-4 b p+b h T+$

$\left.\left.4 I_{e} b p(T-S)\right)\right]+e^{-G x} T\left(2 k_{1}+k_{2}(1+m)(a-b p) T\left(\ln \left(\frac{1+m}{1+m-T}\right)\right)\right)[(1+m)(2 b c+b h T+$

$b k_{2} \delta\left(1+\xi\left(-1+e^{-G x}\right)\left(T+(1+m-T)\left(\ln \left(\frac{1+m}{1+m-T}\right)\right)\right)\right)+(1+m-T)(2 a-4 b p+b h T$

$\left.\left.\left.+4 I_{e} b p(T-S)\right)\right]^{2}\right\}<0$ for any positive value of $T$ and $p$.

Considering the above condition, according to (23), the optimal values are unique, and the total profit function is maximized at $T=T^{*}, p=p^{*}$ and $G=G^{*}$.

\section{Appendix $\mathrm{H}$}

The condition of optimality is that the Hessian matrix of $q_{4}(T, p, G)$ is positive definite, i.e., all eigenvalues of the Hessian matrix $H_{4}=\left[\begin{array}{lll}\frac{d^{2} q_{4}(T, p, G)}{d T^{2}} & \frac{d^{2} q_{4}(T, p, G)}{d T d p} & \frac{d^{2} q_{4}(T, p, G)}{d T d G} \\ \frac{d^{2} q_{4}(T, p, G)}{d p d T} & \frac{d^{2} q_{4}(T, p, G)}{d p^{2}} & \frac{d^{2} q_{4}(T, p, G)}{d p d G} \\ \frac{d^{2} q_{4}(T, p, G)}{d G d T} & \frac{d^{2} q_{4}(T, p, G)}{d G d p} & \frac{d^{2} q_{4}(T, p, G)}{d G^{2}}\end{array}\right]$ are negative definite, where $\frac{d^{2} q_{4}(T, p, G)}{d T^{2}}<0, \frac{d^{2} q_{4}(T, p, G)}{d p^{2}}<0$, and $\frac{d^{2} q_{4}(T, p, G)}{d G^{2}}<0$ as proved in Appendix $\mathrm{H}$ respectively. Additionally, the determinant of the Hessian matrix $\left|H_{4}\right|=\left|\begin{array}{lll}\frac{d^{2} q_{4}(T, p, G)}{d T^{2}} & \frac{d^{2} q_{4}(T, p, G)}{d T d p} & \frac{d^{2} q_{4}(T, p, G)}{d T d G} \\ \frac{d^{2} q_{4}(T, p, G)}{d p d T} & \frac{d^{2} q_{4}(T, p, G)}{d p^{2}} & \frac{d^{2} q_{4}(T, p, G)}{d p d G} \\ \frac{d^{2} q_{4}(T, p, G)}{d G d T} & \frac{d^{2} q_{4}(T, p, G)}{d G d p} & \frac{d^{2} q_{4}(T, p, G)}{d G^{2}}\end{array}\right|_{T=T^{*}, p=p^{*}, G=G^{*}}=\left\{-\left(\frac{1}{4} b^{2} e^{-2 G x} k_{2}{ }^{2}(1+m)^{2}\right.\right.$
$\left.T^{2} x^{2} \xi^{2}\left(\ln \left(\frac{1+m}{1+m-T}\right)\right)^{2}+e^{-g x} T\left(-b I_{e} S^{2}-2 b T\right) \delta x^{2} y\left(\frac{k_{1}}{T}+\frac{k_{2}}{2}(1+m)(a-b p) \ln \left(\frac{1+m}{1+m-T}\right)\right)\right)$
$\left(\left(-h(a-b p)-c I_{c}\right)\left(\frac{1}{2}+\frac{(1+m)^{2}}{(1+m-T)^{2}}\right)-\frac{c(1+m)(a-b p)}{(1+m-T)^{2}}-\left(1-\xi\left(1-e^{-G x}\right) \delta\left[2\left(\frac{k_{2}(1+m)(a-b p)}{2(1+m-T)}\right.\right.\right.\right.$
$\left.\left.\left.-\frac{k_{1}}{T^{2}}\right)+T\left(\frac{k_{2}(1+m)(a-b p)}{2(1+m-T)^{2}}-\frac{2 k_{1}}{T^{3}}\right)\right]\right)+\left(e^{-G x} T \delta x^{2} \xi\right)\left(\frac{k_{1}}{T}+\frac{k_{2}}{2}(1+m)(a-b p) \ln \left(\frac{1+m}{1+m-T}\right)\right)$
$\left[a-b p+\frac{b c(1+m)}{1+m-T}+b h\left(-\frac{1}{2}(1+m)+\frac{(1+m)^{2}}{2(1+m-T)}+\frac{T}{2}\right)+\frac{b k_{2}(1+m) T \delta\left(1-\xi\left(1-e^{-G x}\right)\right.}{2(1+m-T)}+\frac{1}{2} b k_{2}\right.$
$(1+m) \delta\left(1-\xi\left(1-e^{-G x}\right) \ln \left(\frac{1+m}{1+m-T}\right)\right]^{2}-\left(b e^{-G x} k_{2}(1+m) T x^{2} \xi \ln \left(\frac{1+m}{1+m-T}\right)\right)\left(e^{-G x} T x^{2} \xi\right.$
$\left.\left(\frac{k_{2}(1+m)(a-b p)}{2(1+m-T)}-\frac{k_{1}}{T^{2}}\right)+e^{-G x} T x^{2} \xi\left(\frac{k_{1}}{T}+\frac{k_{2}}{2}(1+m)(a-b p) \ln \left(\frac{1+m}{1+m-T}\right)\right)\right)\left[a-b p+\frac{b c(1+m)}{1+m-T}\right.$
$+b h\left(-\frac{1}{2}(1+m)+\frac{(1+m)^{2}}{2(1+m-T)}+\frac{T}{2}\right)+\frac{b k_{2}(1+m) T \delta\left(1-\xi\left(1-e^{-G x}\right)\right.}{2(1+m-T)}+\frac{1}{2} b k_{2}(1+m) \delta(1-\xi(1-$
$\left.\left.e^{-G x}\right) \ln \left(\frac{1+m}{1+m-T}\right)\right]-\left(-b I_{e} S^{2}-2 b T\right)\left(e^{-G x} T x^{2} \xi\left(\frac{k_{2}(1+m)(a-b p)}{2(1+m-T)}-\frac{k_{1}}{T^{2}}\right)+e^{-G x} T x^{2} \xi\left(\frac{k_{1}}{T}+\right.\right.$
$\left.\left.\left.\frac{k_{2}}{2}(1+m)(a-b p) \ln \left(\frac{1+m}{1+m-T}\right)\right)\right)^{2}\right\}<0$ for any positive value of $T, p$, and $G$.

Considering the above condition, according to (23), the optimal values are unique, and the total profit function is maximized at $T=T^{*}, p=p^{*}$, and $G=G^{*}$. 


\section{References}

1. Aliabadi, L.; Yazdanparast, R.; Nasiri, M.M. An inventory model for non-instantaneous deteriorating items with credit period and carbon emission sensitive demand: A signomial geometric programming approach. Int. J. Manag. Sci. Eng. Manag. 2019, 14, 124-136. [CrossRef]

2. Jemai, J.; Do Chung, B.; Sarkar, B. Environmental effect for a complex green supply-chain management to control waste: A sustainable approach. J. Clean. Prod. 2020, 277, 122919. [CrossRef]

3. Oberthür, S.; Ott, H.E. The Kyoto Protocol: International Climate Policy for the 21st Century; Springer Science \& Business Media: Berlin/Heidelberg, Germany, 1999.

4. Hua, G.; Cheng, T.; Wang, S. Managing carbon footprints in inventory management. Int. J. Prod. Econ. 2011, 132, 178-185. [CrossRef]

5. Toptal, A.; Özlü, H.; Konur, D. Joint decisions on inventory replenishment and emission reduction investment under different emission regulations. Int. J. Prod. Res. 2014, 52, 243-269. [CrossRef]

6. Lou, G.X.; Xia, H.Y.; Zhang, J.Q.; Fan, T.J. Investment strategy of emission-reduction technology in a supply chain. Sustainability 2015, 7, 10684-10708. [CrossRef]

7. Bakker, M.; Riezebos, J.; Teunter, R.H. Review of inventory systems with deterioration since 2001. Eur. J. Oper. Res. 2012, 221, 275-284. [CrossRef]

8. Wu, J.; Ouyang, L.-Y.; Cárdenas-Barrón, L.E.; Goyal, S.K. Optimal credit period and lot size for deteriorating items with expiration dates under two-level trade credit financing. Eur. J. Oper. Res. 2014, 237, 898-908. [CrossRef]

9. Tiwari, S.; Cárdenas-Barrón, L.E.; Goh, M.; Shaikh, A.A. Joint pricing and inventory model for deteriorating items with expiration dates and partial backlogging under two-level partial trade credits in supply chain. Int. J. Prod. Econ. 2018, 200, 16-36. [CrossRef]

10. Krass, D.; Nedorezov, T.; Ovchinnikov, A. Environmental taxes and the choice of green technology. Prod. Oper. Manag. 2013, 22, 1035-1055. [CrossRef]

11. Bai, Q.; Xu, J.; Zhang, Y. Emission reduction decision and coordination of a make-to-order supply chain with two products under cap-and-trade regulation. Comput. Ind. Eng. 2018, 119, 131-145. [CrossRef]

12. Goyal, S.K. Economic order quantity under conditions of permissible delay in payments. J. Oper. Res. Soc. 1985, 36, 335-338. [CrossRef]

13. Aggarwal, S.; Jaggi, C. Ordering policies of deteriorating items under permissible delay in payments. J. Oper. Res. Soc. 1995, 46, 658-662. [CrossRef]

14. Kim, J.; Hwang, H.; Shinn, S. An optimal credit policy to increase supplier's profits with price-dependent demand functions. Prod. Plan. Control 1995, 6, 45-50. [CrossRef]

15. Teng, J.-T.; Chang, C.-T. Economic production quantity models for deteriorating items with price-and stock-dependent demand Comput. Oper. Res. 2005, 32, 297-308. [CrossRef]

16. Tsao, Y.-C.; Sheen, G.-J. Dynamic pricing, promotion and replenishment policies for a deteriorating item under permissible delay in payments. Comput. Oper. Res. 2008, 35, 3562-3580. [CrossRef]

17. Chung, C.-J.; Wee, H.-M. Scheduling and replenishment plan for an integrated deteriorating inventory model with stockdependent selling rate. Int. J. Adv. Manuf. Technol. 2008, 35, 665-679. [CrossRef]

18. Sarkar, B. An EOQ model with delay in payments and time varying deterioration rate. Math. Comput. Model. 2012, 55, 367-377. [CrossRef]

19. Wang, W.-C.; Teng, J.-T.; Lou, K.-R. Seller's optimal credit period and cycle time in a supply chain for deteriorating items with maximum lifetime. Eur. J. Oper. Res. 2014, 232, 315-321. [CrossRef]

20. Chen, Z.; Sarker, B.R. Integrated production-inventory and pricing decisions for a single-manufacturer multi-retailer system of deteriorating items under JIT delivery policy. Int. J. Adv. Manuf. Technol. 2017, 89, 2099-2117. [CrossRef]

21. $\mathrm{Wu}$, J.; Teng, J.-T.; Chan, Y.-L. Inventory policies for perishable products with expiration dates and advance-cash-credit payment schemes. Int. J. Syst. Sci. Oper. Logist. 2018, 5, 310-326. [CrossRef]

22. Tai, A.H.; Xie, Y.; He, W.; Ching, W.-K. Joint inspection and inventory control for deteriorating items with random maximum lifetime. Int. J. Prod. Econ. 2019, 207, 144-162. [CrossRef]

23. Mishra, U.; Wu, J.-Z.; Tseng, M.-L. Effects of a hybrid-price-stock dependent demand on the optimal solutions of a deteriorating inventory system and trade credit policy on re-manufactured product. J. Clean. Prod. 2019, 241, 118282. [CrossRef]

24. Shi, Y.; Zhang, Z.; Chen, S.-C.; Cárdenas-Barrón, L.E.; Skouri, K. Optimal replenishment decisions for perishable products under cash, advance, and credit payments considering carbon tax regulations. Int. J. Prod. Econ. 2019, 223, 107514. [CrossRef]

25. Yang, H.-L. Retailer's ordering policy for demand depending on the expiration date with limited storage capacity under supplier credits linked to order quantity and discounted cash flow. Int. J. Syst. Sci. Oper. Logist. 2020, 17, 1-18. [CrossRef]

26. Tiwari, S.; Cárdenas-Barrón, L.E.; Shaikh, A.A.; Goh, M. Retailer's optimal ordering policy for deteriorating items under order-size dependent trade credit and complete backlogging. Comput. Ind. Eng. 2020, 139, 105559. [CrossRef]

27. Saren, S.; Sarkar, B.; Bachar, R.K. Application of various price-discount policy for deteriorated products and delay-in-payments in an advanced inventory model. Inventions 2020, 5, 50. [CrossRef]

28. Sarkar, B.; Dey, B.K.; Sarkar, M.; Hur, S.; Mandal, B.; Dhaka, V. Optimal replenishment decision for retailers with variable demand for deteriorating products under a trade-credit policy. RAIRO Oper. Res. 2020, 54, 1685-1701. [CrossRef] 
29. Khan, M.A.-A.; Shaikh, A.A.; Konstantaras, I.; Bhunia, A.K.; Cárdenas-Barrón, L.E. Inventory models for perishable items with advanced payment, linearly time-dependent holding cost and demand dependent on advertisement and selling price. Int. J. Prod. Econ. 2020, 230, 107804. [CrossRef]

30. Das, S.; Khan, M.A.-A.; Mahmoud, E.E.; Abdel-Aty, A.-H.; Abualnaja, K.M.; Shaikh, A.A. A production inventory model with partial trade credit policy and reliability. Alex. Eng. J. 2021, 60, 1325-1338. [CrossRef]

31. Sebatjane, M.; Adetunji, O. Optimal lot-sizing and shipment decisions in a three-echelon supply chain for growing items with inventory level-and expiration date-dependent demand. Appl. Math. Model. 2021, 90, 1204-1225. [CrossRef]

32. Huang, Y.-S.; Ho, J.-W.; Jian, H.-J.; Tseng, T.-L.B. Quantity discount coordination for supply chains with deteriorating inventory. Comput. Ind. Eng. 2021, 152, 106987. [CrossRef]

33. Das, S.C.; Manna, A.K.; Rahman, M.S.; Shaikh, A.A.; Bhunia, A.K. An inventory model for non-instantaneous deteriorating items with preservation technology and multiple credit periods-based trade credit financing via particle swarm optimization. Soft Comput. 2021, 53, 1-20.

34. Jaber, M.Y.; Glock, C.H.; El Saadany, A.M. Supply chain coordination with emissions reduction incentives. Int. J. Prod. Res. 2013, 51, 69-82. [CrossRef]

35. Dye, C.-Y.; Yang, C.-T. Sustainable trade credit and replenishment decisions with credit-linked demand under carbon emission constraints. Eur. J. Oper. Res. 2015, 244, 187-200. [CrossRef]

36. Lu, C.-J.; Yang, C.-T.; Yen, H.-F. Stackelberg game approach for sustainable production-inventory model with collaborative investment in technology for reducing carbon emissions. J. Clean. Prod. 2020, 270, 121963. [CrossRef]

37. Mishra, U.; Wu, J.-Z.; Sarkar, B. A sustainable production-inventory model for a controllable carbon emissions rate under shortages. J. Clean. Prod. 2020, 256, 120268. [CrossRef]

38. Battini, D.; Calzavara, M.; Isolan, I.; Sgarbossa, F.; Zangaro, F. Sustainability in material purchasing: A multi-objective economic order quantity model under carbon trading. Sustainability 2018, 10, 4438. [CrossRef]

39. Tiwari, S.; Daryanto, Y.; Wee, H.M. Sustainable inventory management with deteriorating and imperfect quality items considering carbon emission. J. Clean. Prod. 2018, 192, 281-292. [CrossRef]

40. Taleizadeh, A.A.; Hazarkhani, B.; Moon, I. Joint pricing and inventory decisions with carbon emission considerations, partial backordering and planned discounts. Ann. Oper. Res. 2020, 290, 95-113. [CrossRef]

41. Yang, L.; Zhang, Q.; Ji, J. Pricing and carbon emission reduction decisions in supply chains with vertical and horizontal cooperation. Int. J. Prod. Econ. 2017, 191, 286-297. [CrossRef]

42. Bai, Q.; Jin, M.; Xu, X. Effects of carbon emission reduction on supply chain coordination with vendor-managed deteriorating product inventory. Int. J. Prod. Econ. 2019, 208, 83-99. [CrossRef]

43. Qin, J.; Bai, X.; Xia, L. Sustainable Trade credit and replenishment policies under the cap-and-trade and carbon tax regulations. Sustainability 2015, 7, 16340-16361. [CrossRef]

44. Mishra, U.; Wu, J.-Z.; Tsao, Y.-C.; Tseng, M.-L. Sustainable inventory system with controllable non-instantaneous deterioration and environmental emission rates. J. Clean. Prod. 2020, 244, 118807. [CrossRef]

45. Shaw, B.K.; Sangal, I.; Sarkar, B. Joint effects of carbon emission, deterioration, and multi-stage inspection policy in an integrated inventory model. In Optimization and Inventory Management; Springer: Singapore, 2020; pp. 195-208.

46. Gao, X.; Chen, S.; Tang, H.; Zhang, H. Study of optimal order policy for a multi-period multi-raw material inventory management problem under carbon emission constraint. Comput. Ind. Eng. 2020, 148, 106693. [CrossRef]

47. Mishra, U.; Wu, J.-Z.; Sarkar, B. Optimum sustainable inventory management with backorder and deterioration under controllable carbon emissions. J. Clean. Prod. 2021, 279, 123699. [CrossRef]

48. Sarkar, B.; Sarkar, M.; Ganguly, B.; Cárdenas-Barrón, L.E. Combined effects of carbon emission and production quality improvement for fixed lifetime products in a sustainable supply chain management. Int. J. Prod. Econ. 2021, 231, 107867. [CrossRef]

49. Liu, M.-1.; Li, Z.-h.; Anwar, S.; Zhang, Y. Supply chain carbon emission reductions and coordination when consumers have a strong preference for low-carbon products. Environ. Sci. Pollut. Res. 2021, 46, 1-15.

50. Ullah, M.; Asghar, I.; Zahid, M.; Omair, M.; Alarjani, A.; Sarkar, B. Ramification of remanufacturing in a sustainable three-echelon closed-loop supply chain management for returnable products. J. Clean. Prod. 2021, 290, 125609. [CrossRef]

51. Cambini, A.; Martein, L. Generalized Convexity and Optimization: Theory and Applications; Springer Science \& Business Media: Riverside, CA, USA, 2018; Volume 616. 